$$
\begin{aligned}
& \text { الهضم الهوائي للنفايات الصلبة البلدية في مدينة الموصل وتحويلها إلى دبال }
\end{aligned}
$$

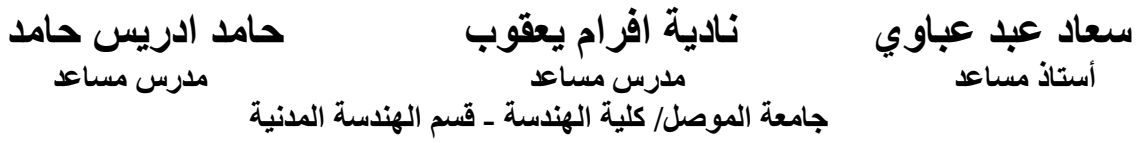

$$
\begin{aligned}
& \text { الملخص }
\end{aligned}
$$

تضمن البحث إجراء عملية هضم هوائي لنماذج من النفايات المنزلية الصلبة الممزوجة بشكل عشوائي المئي لتمثل

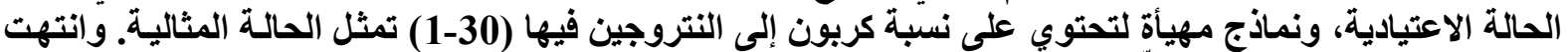

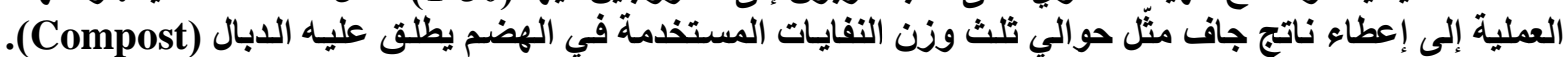

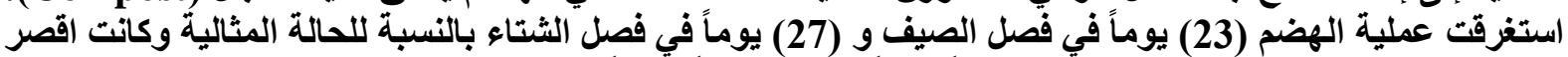

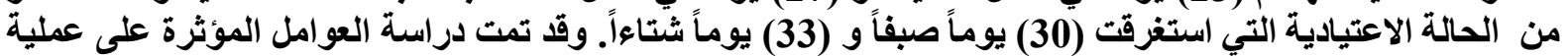

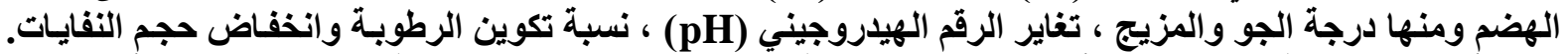

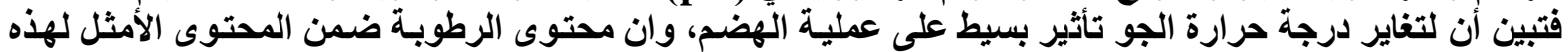

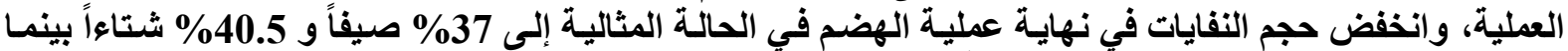

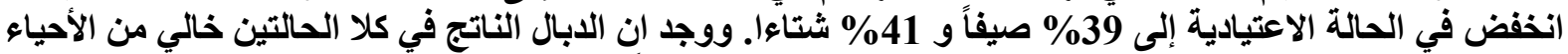

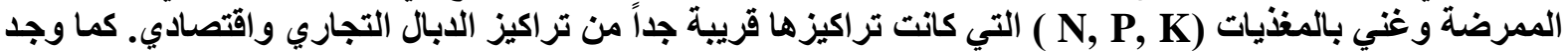
ان تراكيز المعادن الثقيلة فيه كاتت ضمن محددات الابال القيات التيزية .

\title{
Aerobic Composting of Municipal Solid waste in Mosul City
}

\author{
Soad A. Abawi \\ Nadia A. Yakoob \\ Hamid A. Hamid \\ Assist. Professor \\ Assist. lecturer \\ Assist.Lecturer \\ University of Mosul -College of Engineering-Civil Department
}

\begin{abstract}
An aerobic digestion for solid waste samples which had been mixed randomly to represent the normal (real) case, and for samples prepared to have Carbon to Nitrogen $\mathrm{C}: \mathrm{N}$ equal (1-30) as an ideal case. The result of this process was a dry matter has 1:3 the original weight of the used solid waste in the digestion and this product was called compost. The duration of digestion for ideal case was (23) days in summer and (27) days in winter, while for normal case it was $(30,33)$ in summer and winter respectively. In this research several factors effecting on the digestion such as (temperature of air and mix, $\mathrm{pH}$ variation, water content and volume reducing of solid mixture were studied). we concluded that the effect of air temperature variation was mild on digestion, and the water content was in the ideal range of the process,. The solid waste volume decreased in the end of digestion process for ideal case to $(37,40.5) \%$, while decreased to $(39,41) \%$ for real case in the summer and winter respectively. The produced compost in both case was shown free from pathogenic microorganism and rich in nutrients $(N, P, K)$ and their concentrations approach to commercial compost as well as their economic value. It has been found that the heavy metals concentrations in the resultant compost were in the standard limits.
\end{abstract}




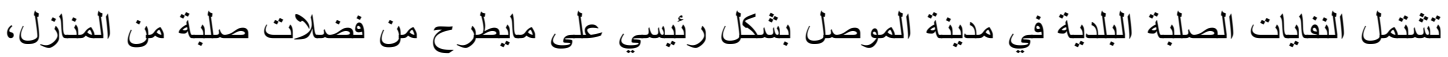

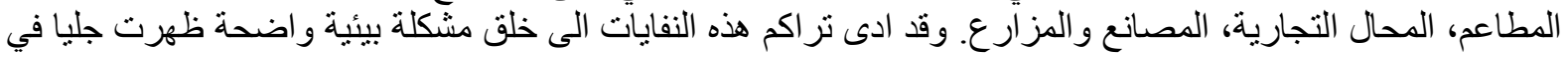

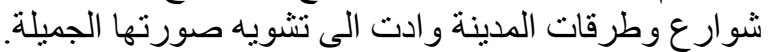

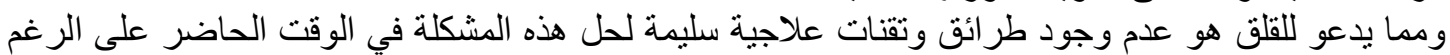

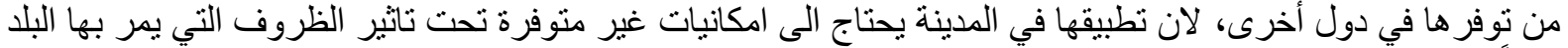

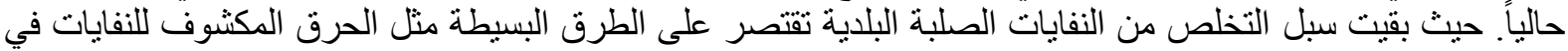

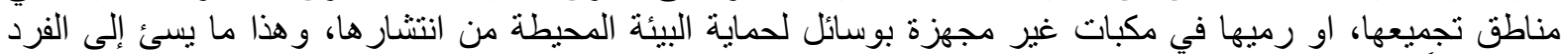

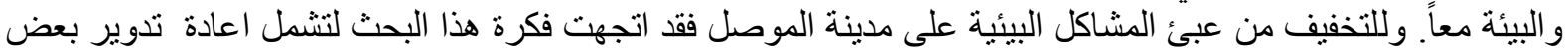

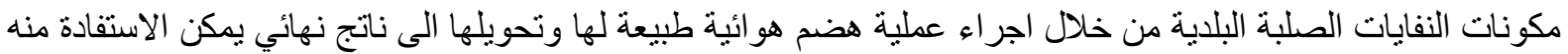

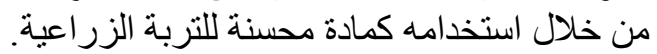

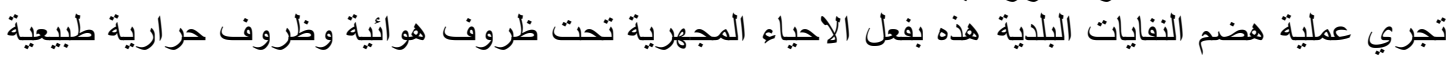

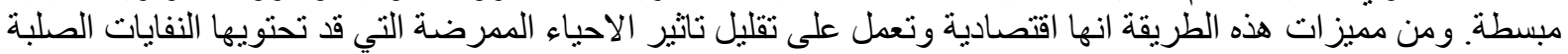

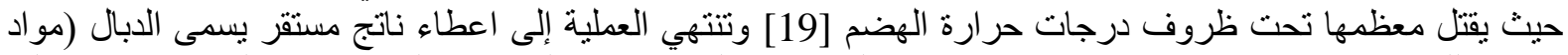

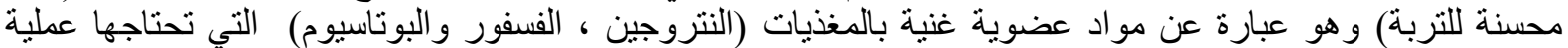
الانبات، ويفيد في تخفيف التربة التقيلة وتحسين تركيب التربة وزيادة قدرتها على الاحتفاظ بالماء [3].

\section{أهداف البحث}

1. التقليل من حجم النفايات الصلبة البلدية بإجراء عملية هضم هو ائي عليها وتحويلها إلى دبال.

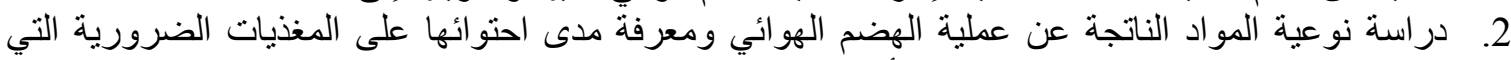
يجب توفر ها في السماد ومدى خلو ها من الأحباء الممرضة.

\section{استعراض المراجع}

قامـت الباحتـة [1] بدر اسـة خصـائص وكميـات النفايـات الصلبة البلديـة في مدينـة الموصـل بنو عيهـا (المنزلـي

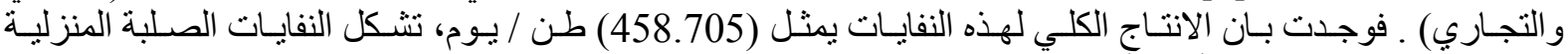

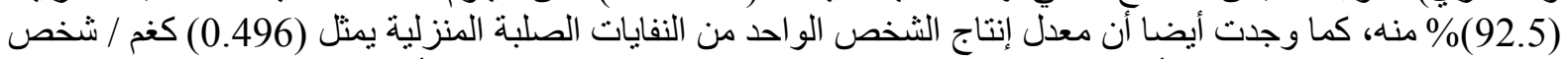

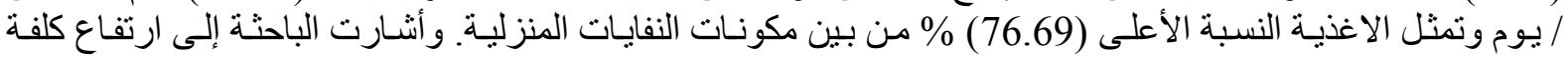

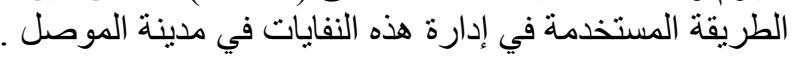

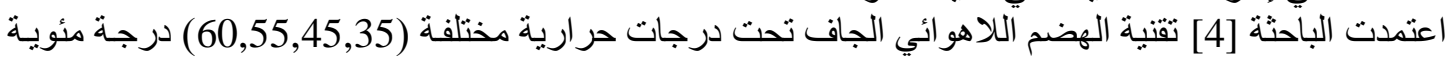

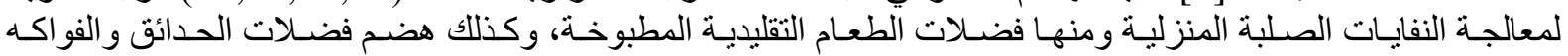

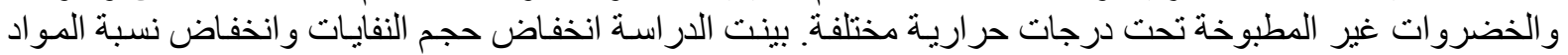

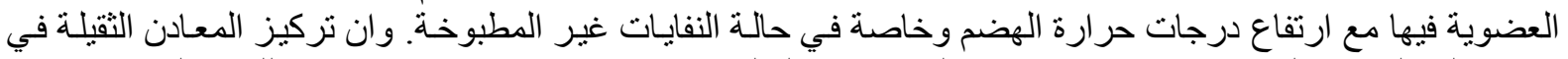

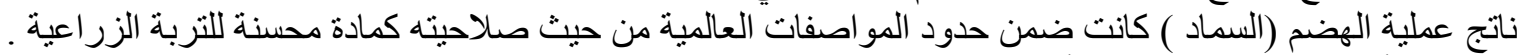

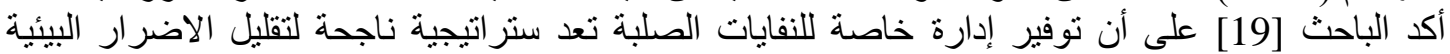

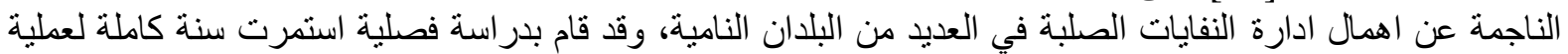

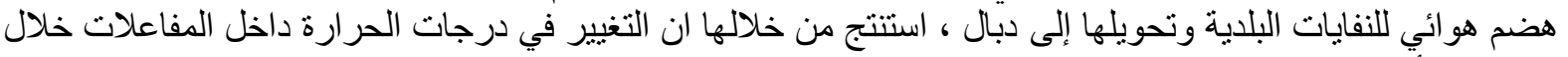

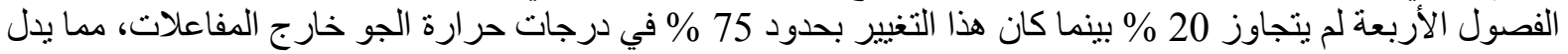

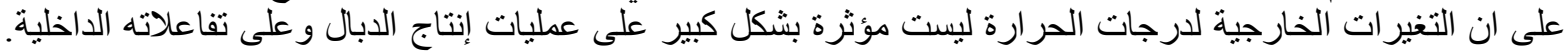

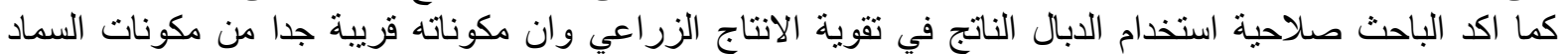

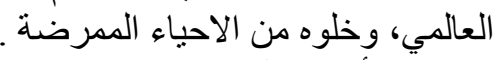

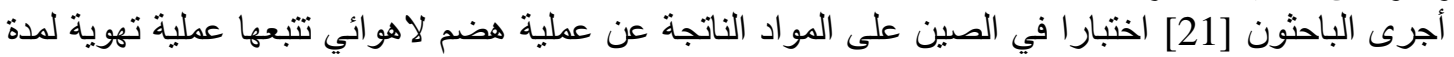

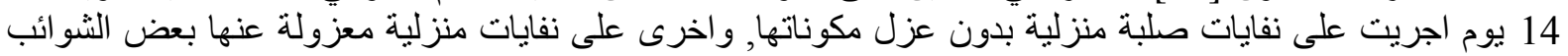

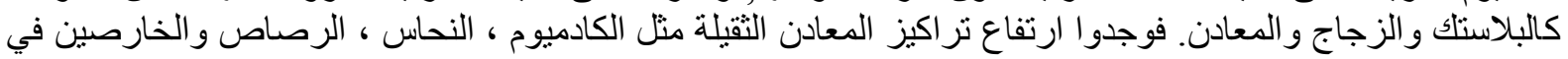

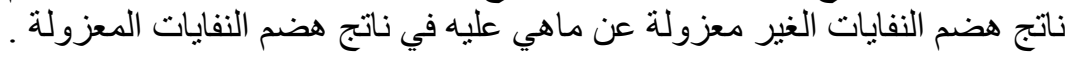


اعتبر الباحثون [5] أن عدم إدارة النفايات الصلبة البلدية في كل مدن نيجيريا تعد من المشاكل المهمة المؤثرة

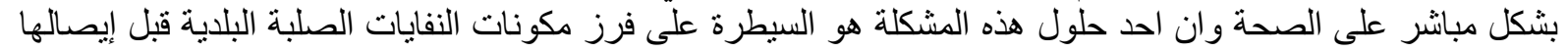

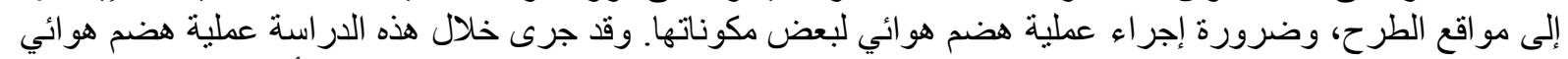

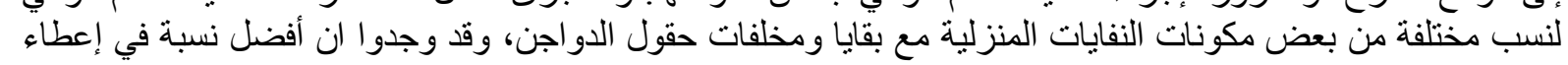

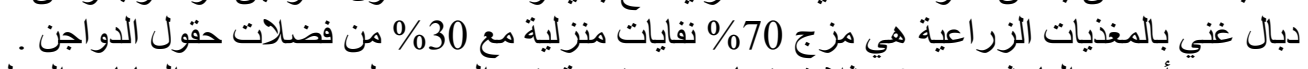

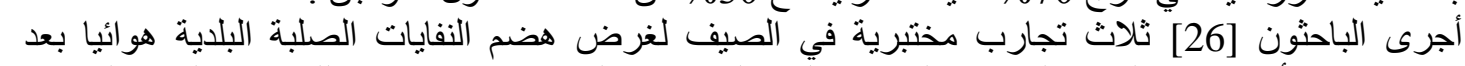

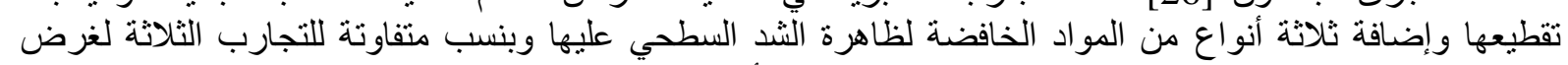

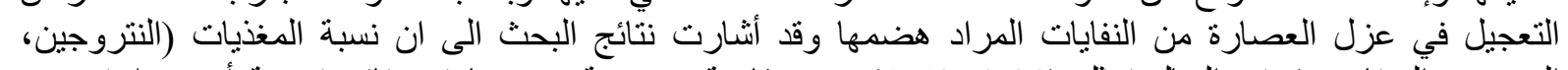

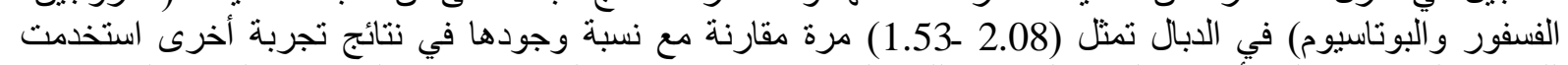

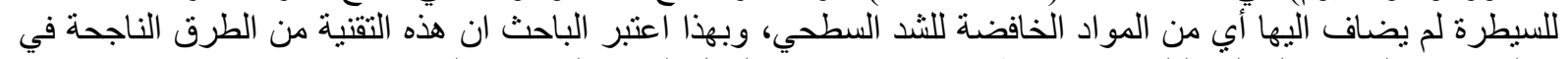

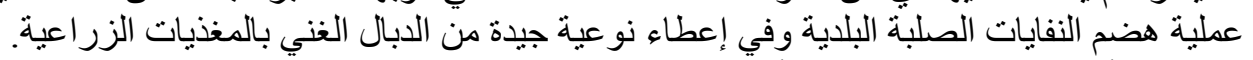

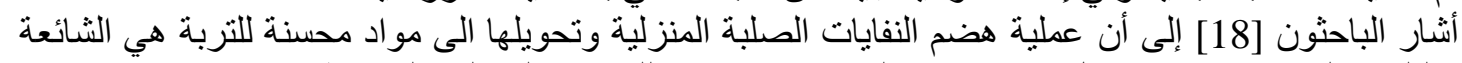

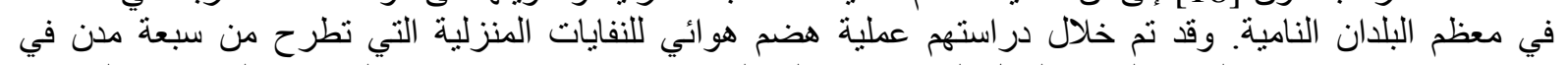

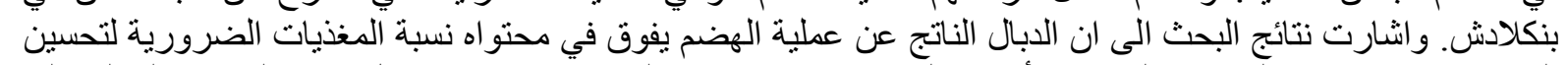

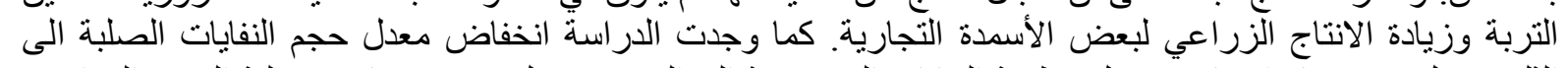

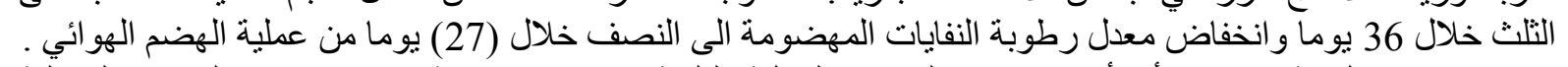

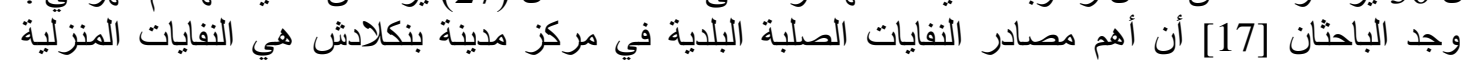

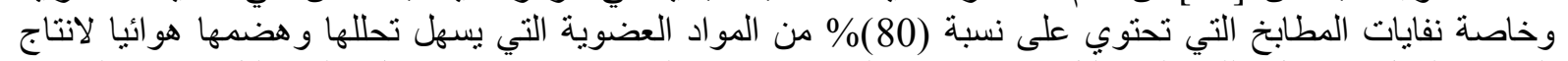

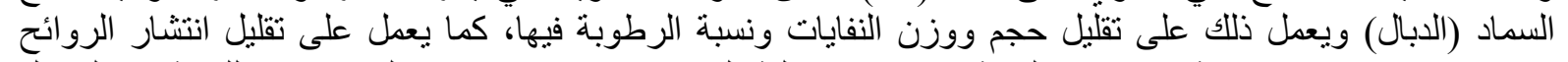

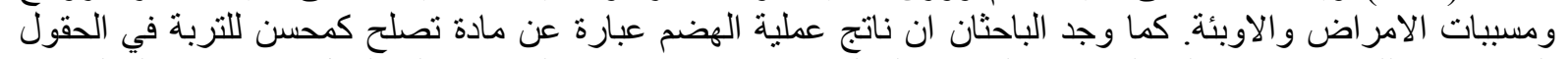

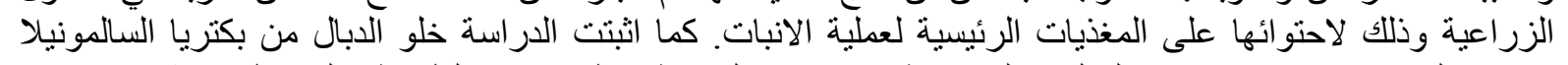

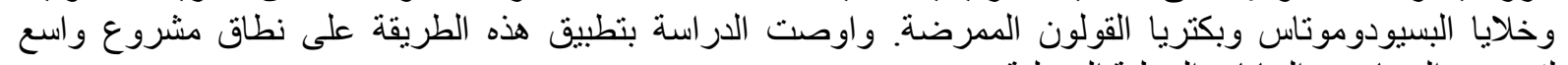

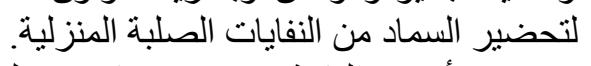

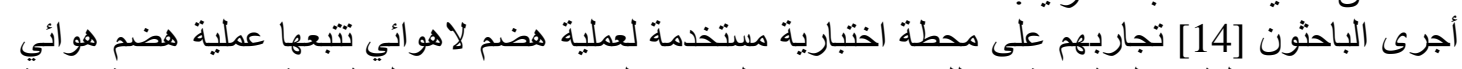

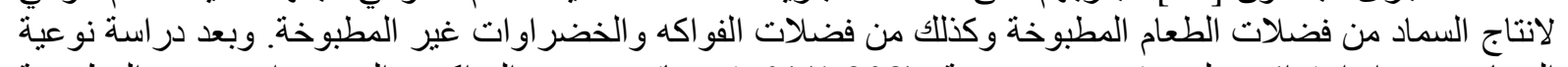

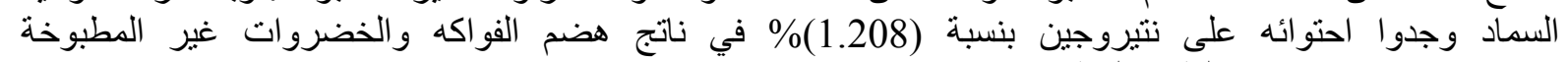

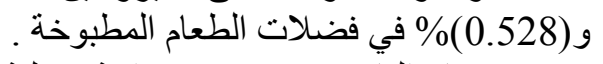

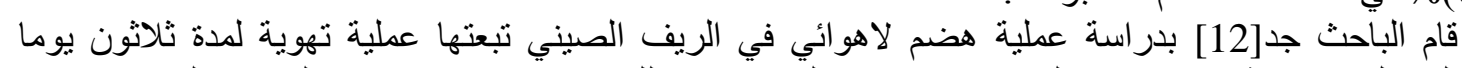

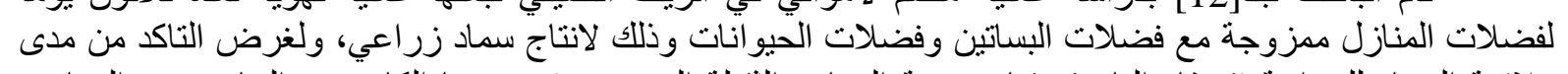

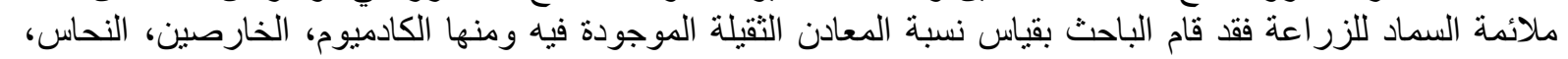

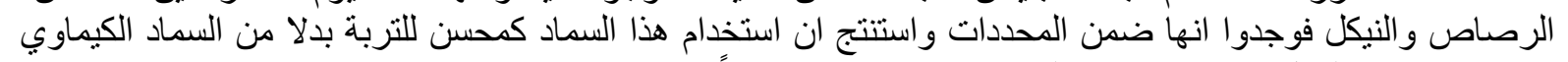

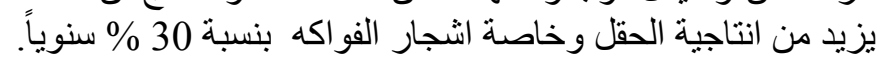

\section{المواد وطر ائق العمل

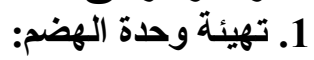
تطلب البحث إنشاء نموذج حقلي اختباري لهضم النفايات الصلبة المنزلية كالنموذج المعتمد من قبل الباحث

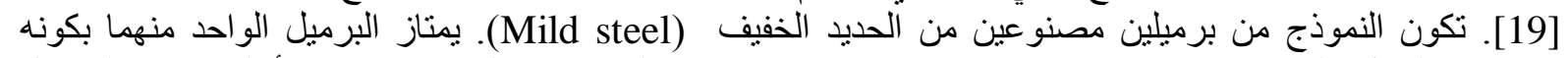
اسطو اني الثنكل يبلغ ارتفاعه (86) سم وقطره (53) سم وسعته الإجمالية (200) لتزر مفتوح من الأعلى. و هذه البرامين البيل وقد نم اجر اء بعض التحويرات على هذه البراميل كما مبين في الثكل (1) لضرورة إيصال البعال الهواء داخلها منوفرة محلياً.

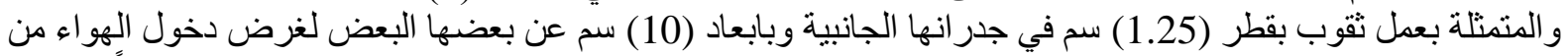

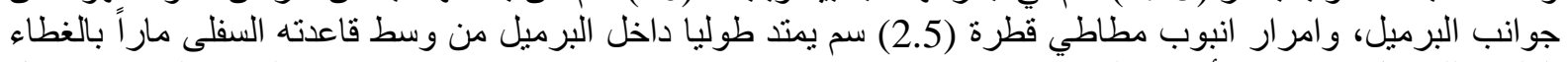

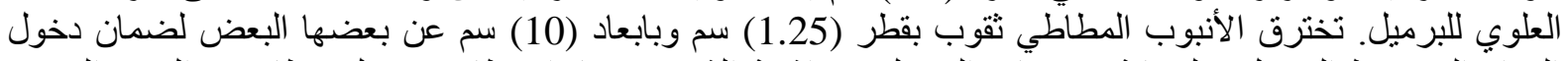

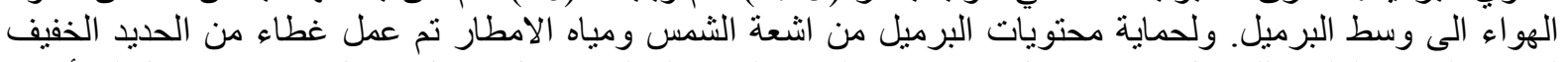

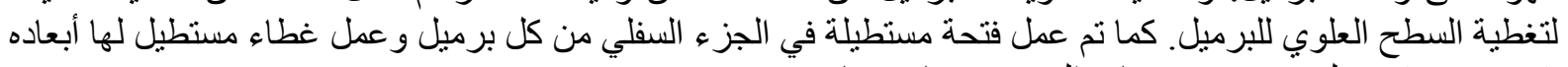

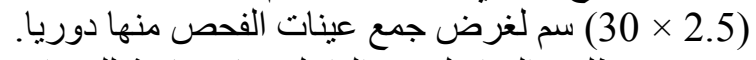

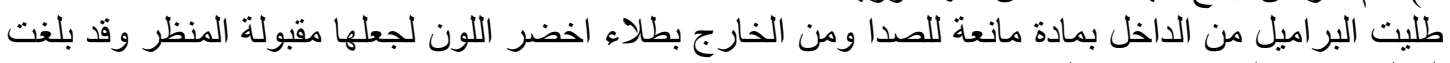
كلفة البرميل اللو احد مع التحوير اتل حوالي (15000) دينار عر اقي . 

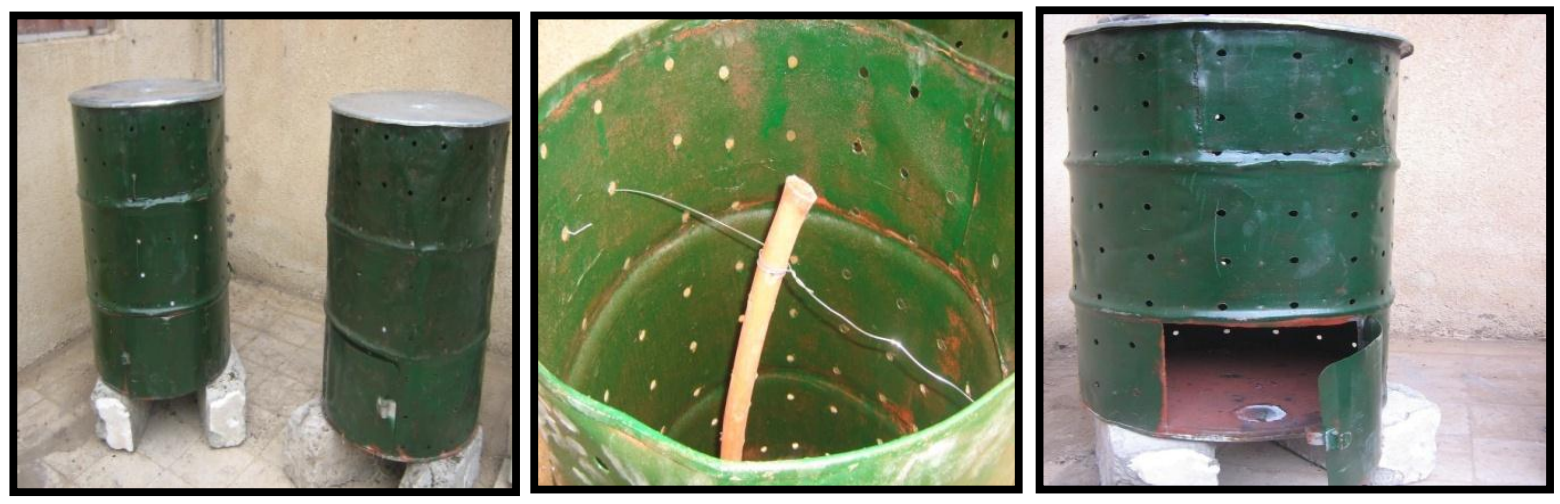

الثكل (1) صور فوتوغرافية للبراميل المستخدمة في البحث تظهر فيها التحويرات التي اجريت عليها

2. تهيئة النفايات الصلبة المنزلية : تم اعتماد حالتين من تر اكيب النفايات الصلبة البلدية أثناء عملية الهضم في فصل الثنتاء للفترة من 2009/5/12/22 2009/1/30 وحالثين في فصل الصيف خلال الفترة 2009/5/3 - 2009/7/11 وهي:

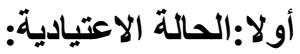

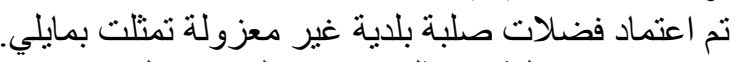

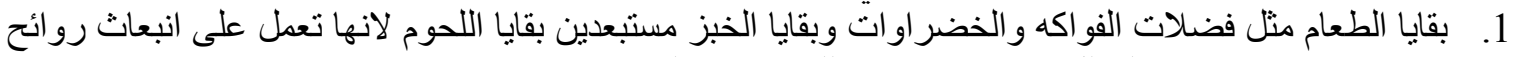

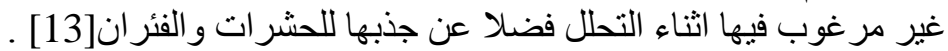

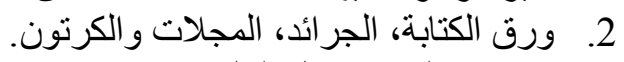

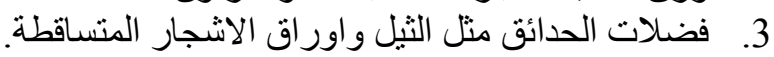

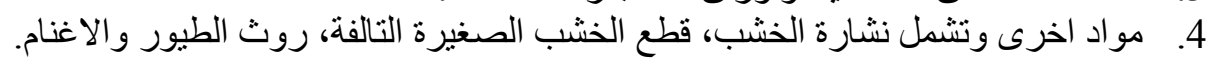

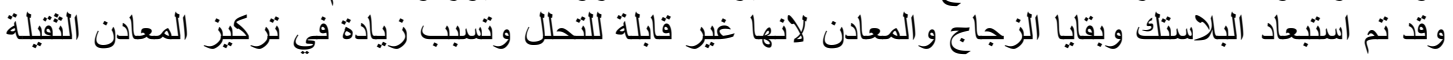

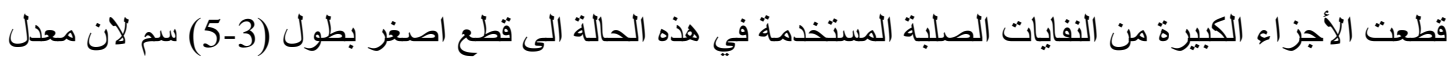

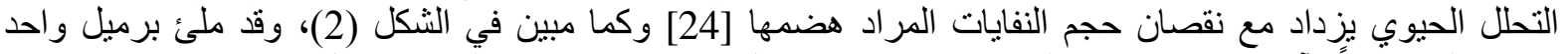

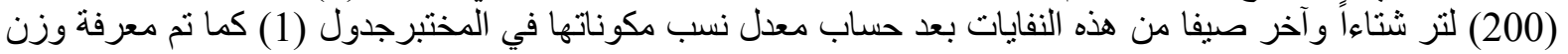
النفايات التي تملا كل برميل.

الجدول (1) نسب مكونات النفايات الصلبة المنزلية المعتمدة في الحالة الاعتيادية

\begin{tabular}{|c|c|c|}
\hline \multicolumn{2}{|c|}{ معدل النسبة المئوية في البرميل الواحد } & \multirow[t]{2}{*}{ نوع الفضلات } \\
\hline صيفاً & شتثاعاً & \\
\hline$\% 85.0$ & $\% 84.0$ & بقايا الطعام \\
\hline$\% 7.5$ & $\% 9.5$ & الورق والكارتون \\
\hline$\% 7.0$ & $\% 6.0$ & فضلات حدائق \\
\hline$\% 0.5$ & $\% 0.5$ & مواد اخرى \\
\hline$\% 100$ & $\% 100$ & \\
\hline
\end{tabular}

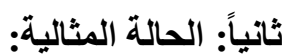

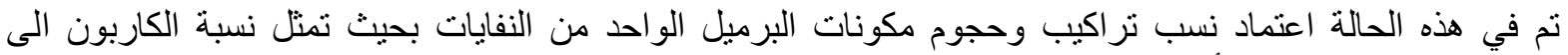

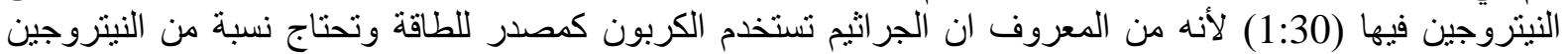

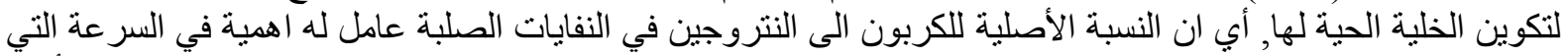

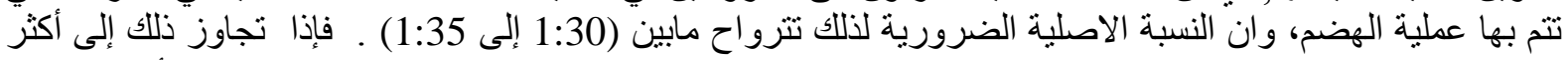
من (1:40) فان الوقت اللازم للهضم يزداد تبعا لذللك، ولتحسين هذا يمكن إضافة النتروجين إلى النفايات. أما إذا كانت الته 
النسبة اقل من (1:30) فانها تكون غير مستحبة في الهضم ويمكن تحسينها بإضافة الكربون اليها [3,15].

قيم الكاربون الى النيتروجن المذكورة في الجدول (2) للحصول فئ على نسبة الكربون الى الى النتروجين تمنل (1:30)

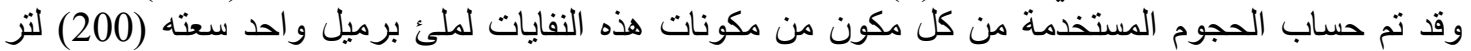

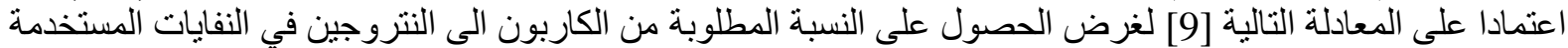

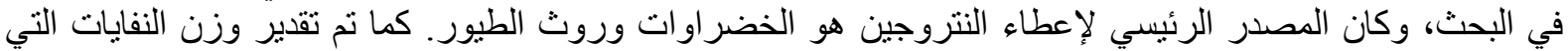
ملئت كل برميل.

$$
\begin{aligned}
& \frac{C}{N} \times \text { مجموع عدد اللترات لكل مكون من النفايات } \\
& \text { مجموع عدد اللترات لجميع مكونات النفايات } \\
& C: N=\frac{35(35: 1)+57(16: 1)+6(175: 1)+2(350: 1)+8(10: 1)+4(20: 1)+18(45: 1)+48(18: 1)+22(15: 1)}{200 L} \\
& \mathrm{C}: \mathrm{N}=30.255: 1 \approx 30: 1 \\
& \text { N: Cلخليط }
\end{aligned}
$$

\begin{tabular}{|c|c|c|c|}
\hline 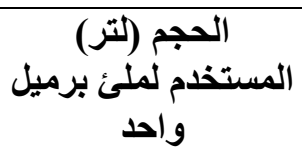 & نسبة الكاربون:نيتروجن & الكاربون:نيتروجن في & النفايات \\
\hline 35 لتر & $1: 35$ & $1: 35$ & الفاكهة \\
\hline 57 & 1: 16 & 1: (20-12) & الخضروات \\
\hline 6 & $1: 175$ & $1:(200-150)$ & الورق العادي \\
\hline 2 & 1:350 & $1:(500-200)$ & نشارة الخشب \\
\hline 8 & 1: 10 & $1: 10$ & روث الطيور \\
\hline 4 & 1: 20 & 1: 20 & روث البقز \\
\hline 18 & $1: 45$ & $1: 45$ & أوراق الأشجار المتساقطة \\
\hline 48 & 1: 18 & 1:(25-12) & ثيل (حشيش) \\
\hline 22 & $1: 15$ & 1: 15 & بقايا الخبز \\
\hline
\end{tabular}

جدول (2) قيم نسب الكاريون : نيتروجن وحجوم مكونات النفايات الصلبة
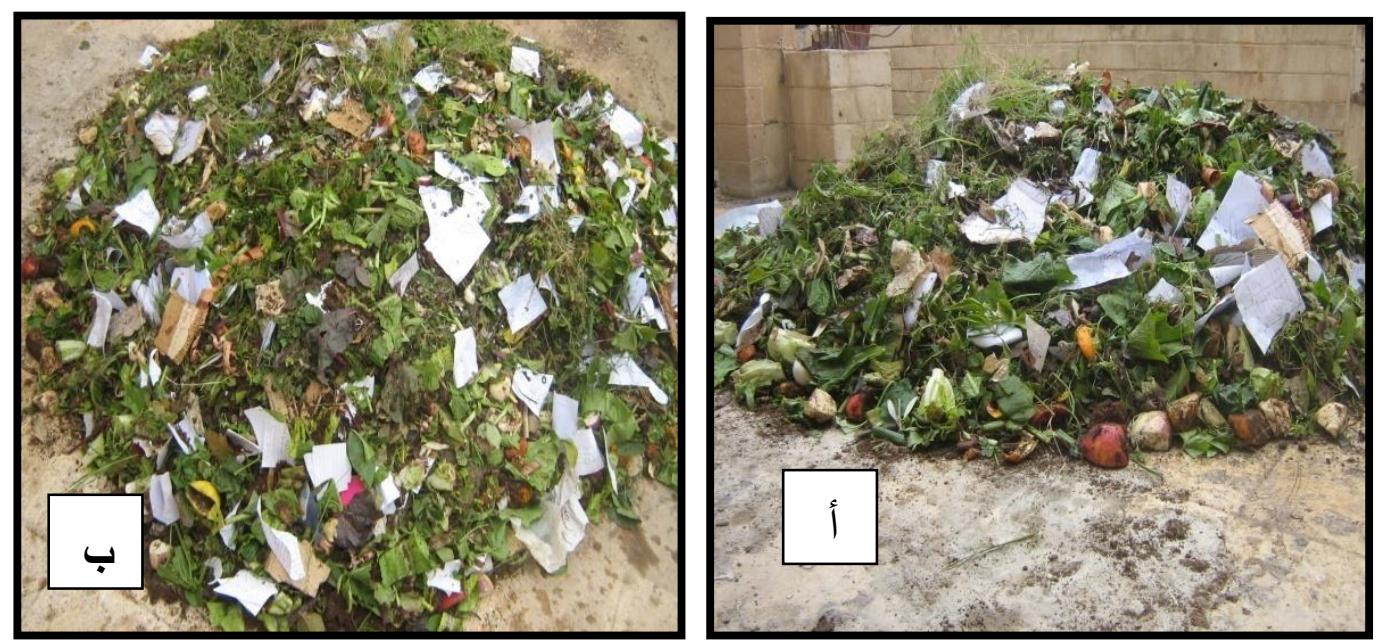

الثكل (2) صور فوتوغر فية للنفايات الصلبة بعد تقطيعها أـ الحالة الاعتيادية بـ الحالة المثالية 


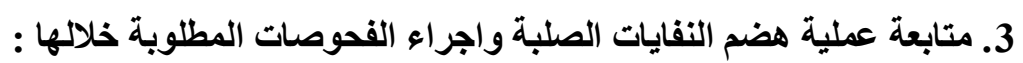

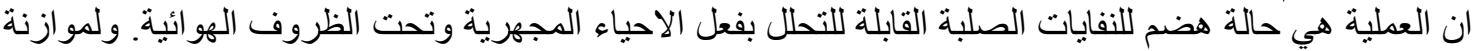

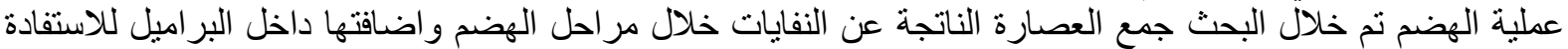
من المغذيات الموجودة فيها لمبها [13]. وقد أجريت الفحوصات المهمة يوميا لمتابعة سير عملية الهضم ومنها درجة حرارة الهوات الجو ودرجة حرارة النفايات،

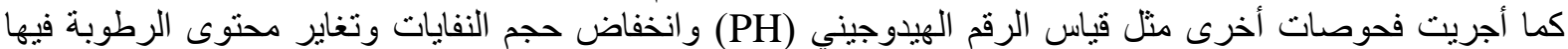

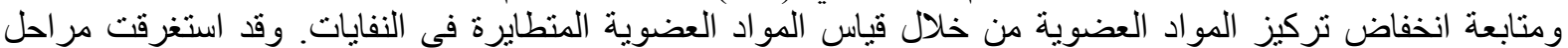

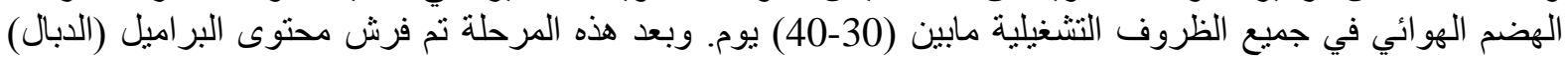

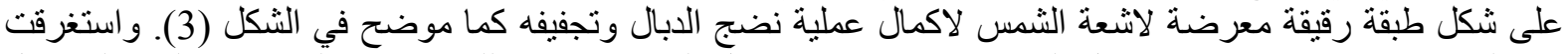

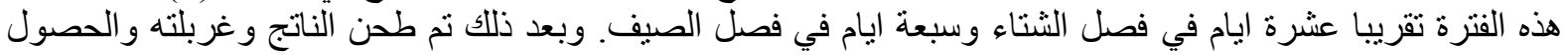

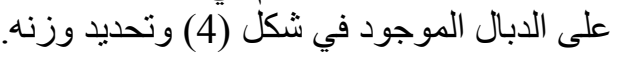

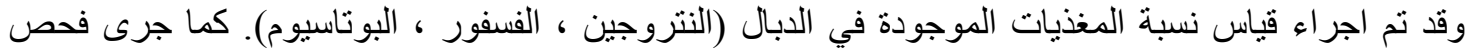

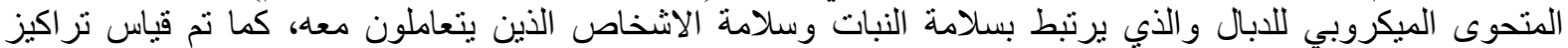

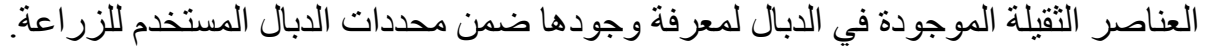

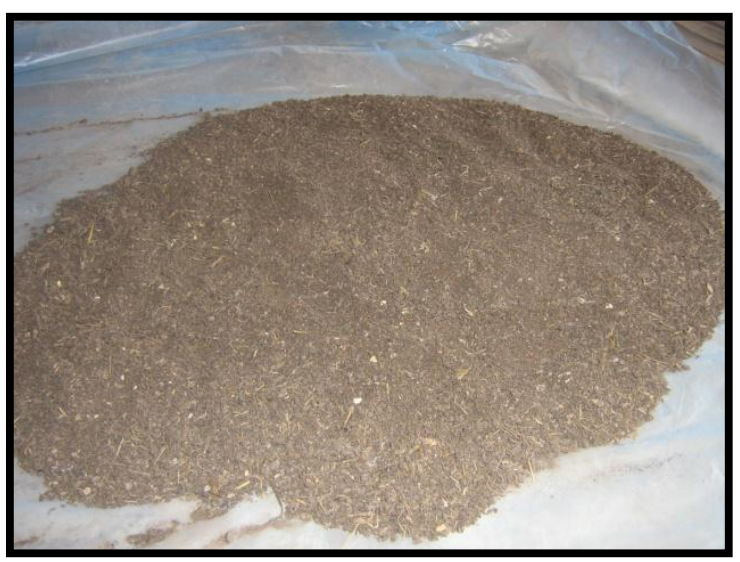

الشكل (4) صورة فوتوغر افية للابال بعد نضجه

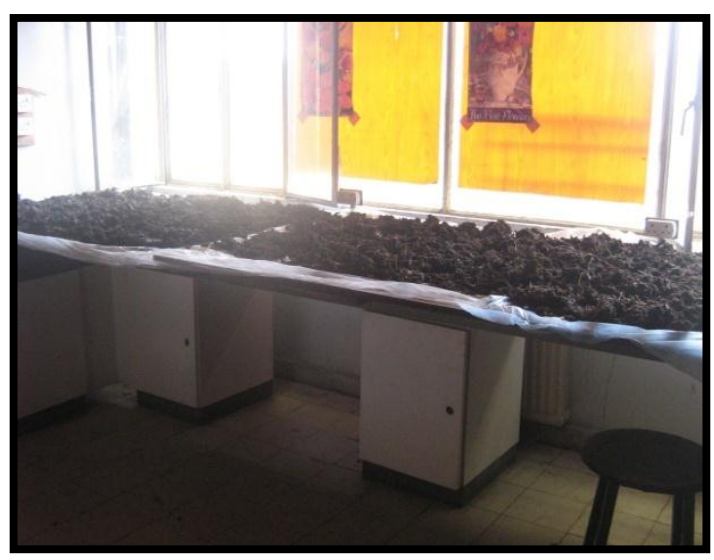

الشكل (3) صورة فوتوغرافية لعملية فرش الابال لإكمال نضجه فرونه

\section{الفحوصات المختبرية}

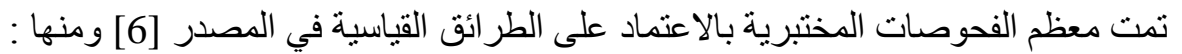

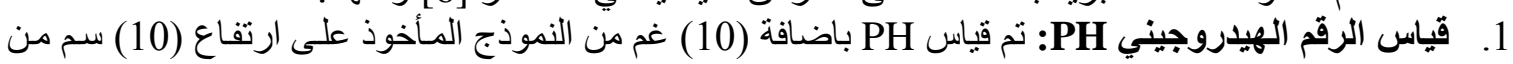

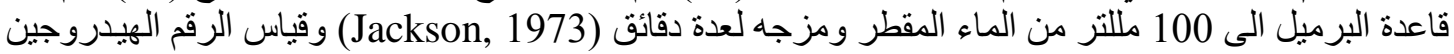

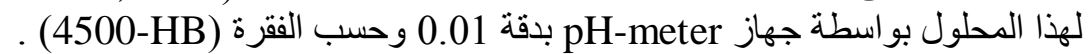

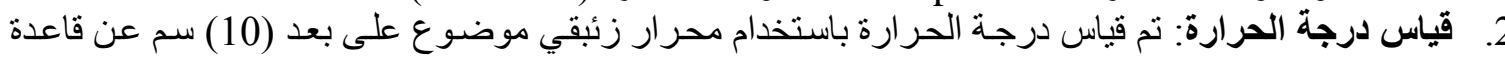
البرميل و بعمل بالنظام المئوي بدقة 0.10 مُ وحسب درائ الفقرة (212). 3. قياس رطوبة النفايات: تم قباس الرطوبة باعتماد وزن النفايات قبل وبعد تجفيفها وبأستخدام جفنة خزفية فئة وميزان

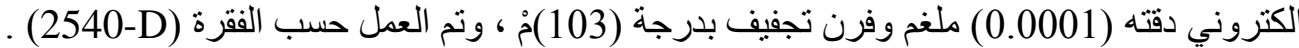

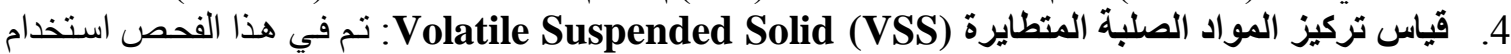

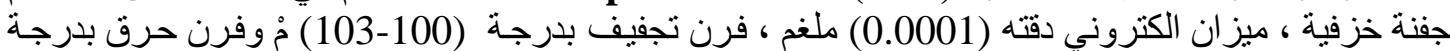

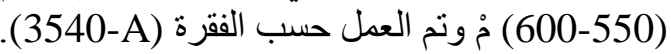
5. قياس تركيز الفوسفات: تم قياس الفوسفات بطريقة كلوريد القصديروز للنماذج المهضومة وقد تم اعتمـاد الفقرة (4500-D)

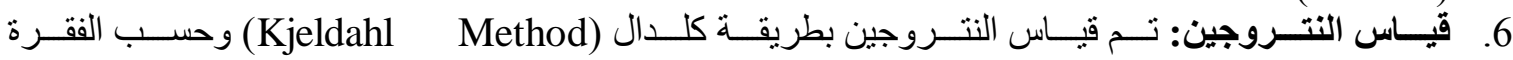
(420-A)

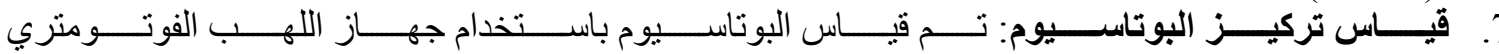
(Flame photometer) 


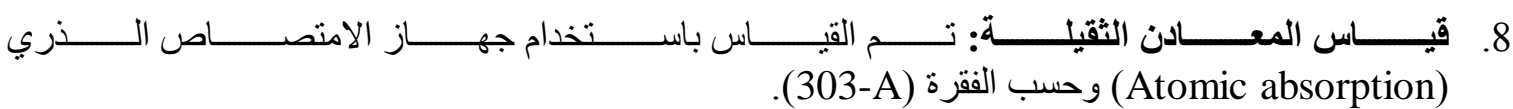

9. التحليل الميكروبي في الدبال : نم تحضير النموذج بمز ج (303) (1.0) غم من الدبال قي (10) مللتر من المـاء المقطر المعقم ومن ثم إجراء الفحوصات الحيوية الحية عليه في مختبرات كلية العلوم /قنسم علوم الحياة.

النتائج والمناقشة

1 1. تغاير درجة الحرارة خلال فترة تكوين الابال:

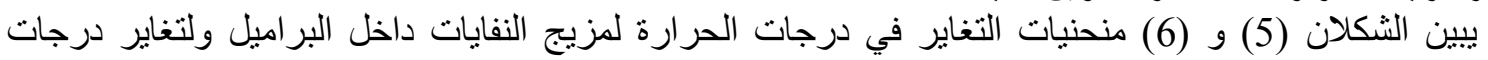

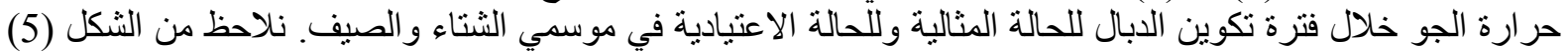

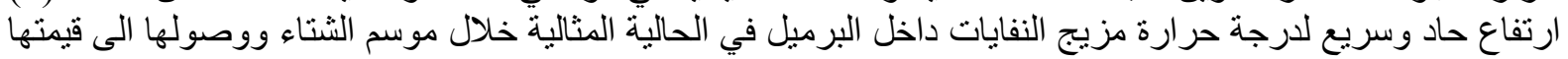

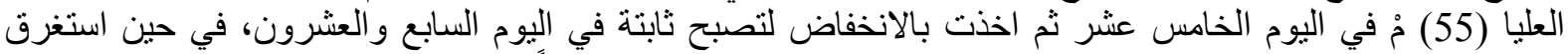

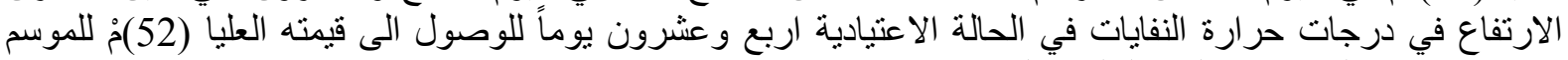

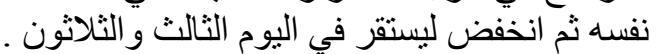

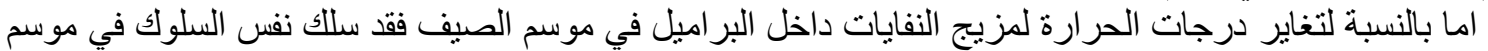

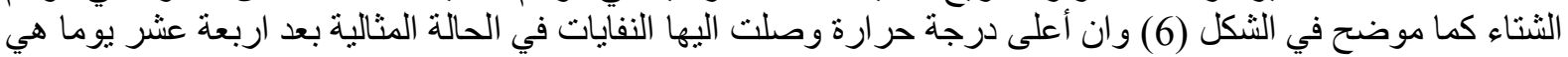

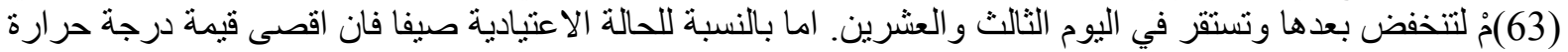

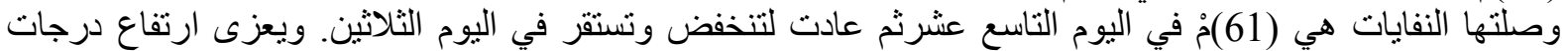

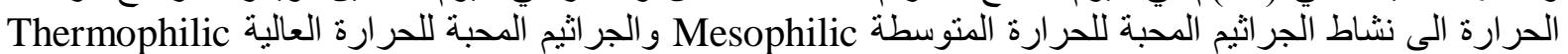

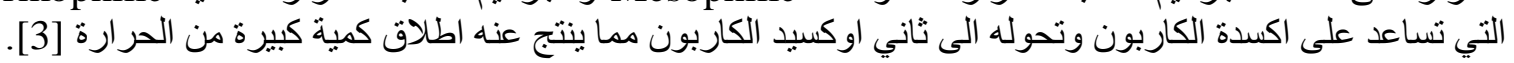

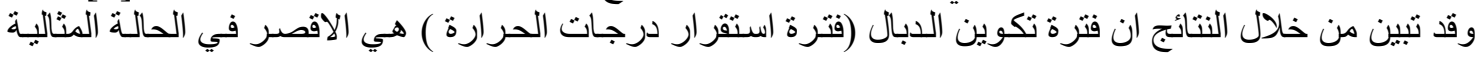

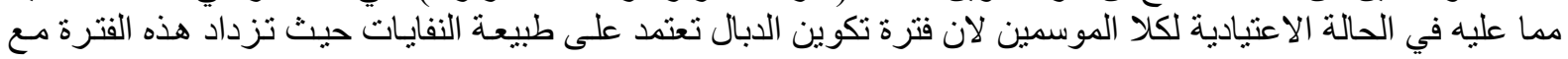

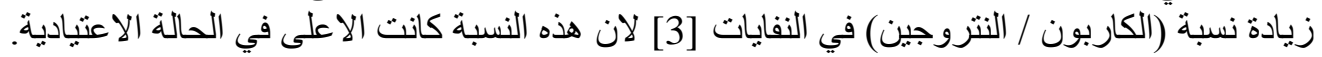

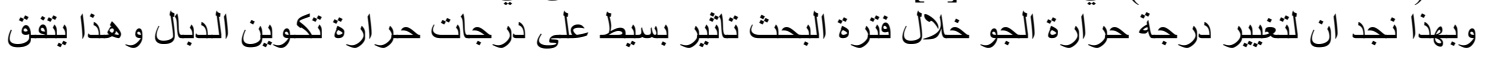

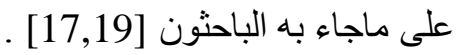

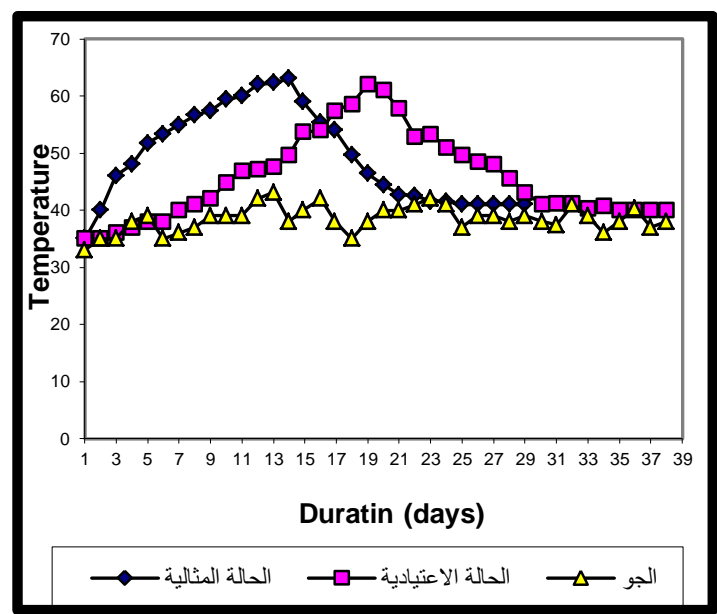

الثكل(6) تغاير درجات حرارة مزيج النفايات داخل فيرة

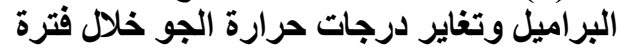
تكوين الدبال في موسم الصيف

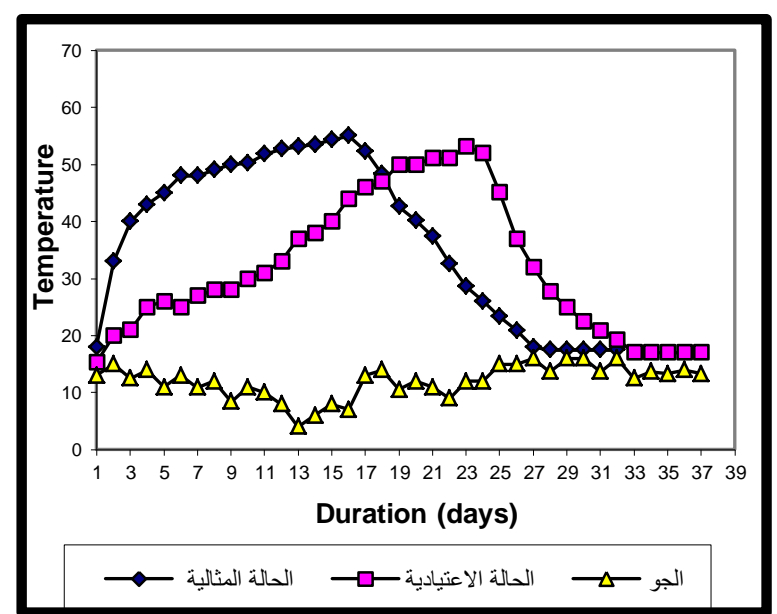

الشكل(5) تغاير درجات حرارة مزيج النفايات داخل

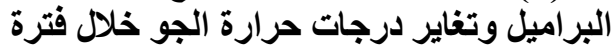
تكوين الابال في موسم الثتاء

2. تغاير قيمة الرقم الهلروجيني خلال فترة تكوين الابال .

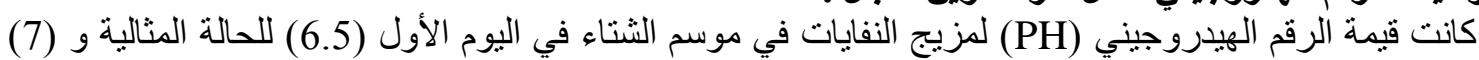

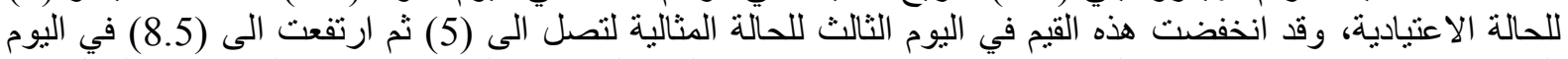

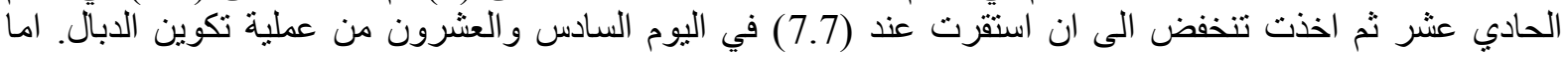
بالنسبة للحالة الاعتيادية في نفس الموسم فقد حصل ادنى انخفاض للرقم العيدروجيني (5.2) في اليوم السادس ومن ثم 
ارتفعت لتصل الى 8.5 في اليوم الثاني والعشرون لتنخفض بعدها وتسنتر عند (7.8) في اليوم الثالث والثلاثون كما

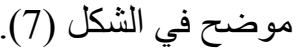
اما بالنسبة لموسم الصيف يلاحظ من الثكل (8) ان قيمة الرقم الهيدروجيني لمزيج النفايات في اليوم الاول كان (6.7)

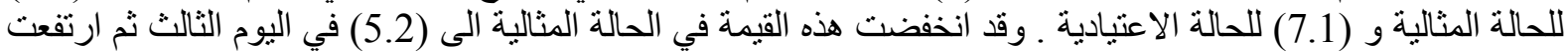

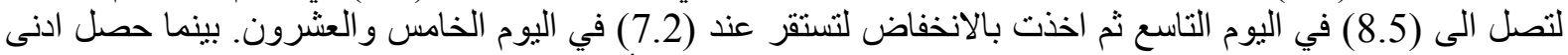

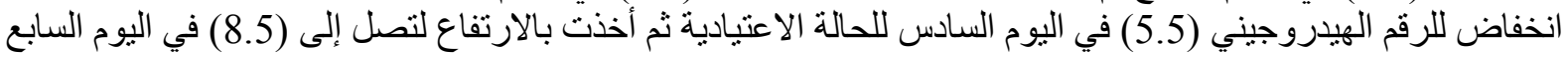

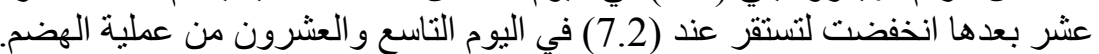

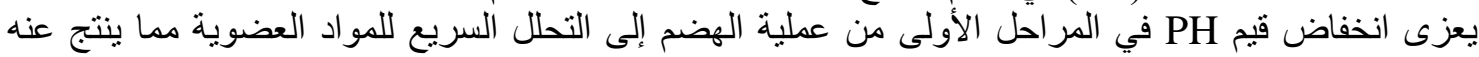

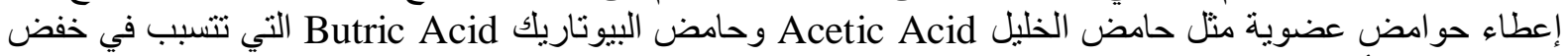

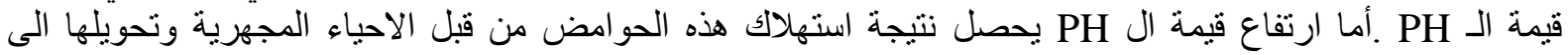

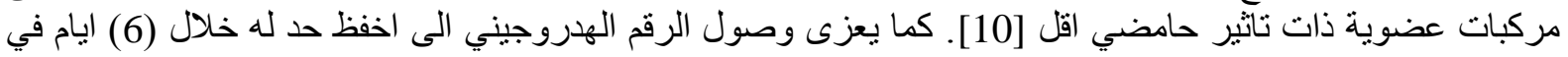
الحالة الاعتبادية و (3) ايام في الحالة المثالية هو انخفاض المواد العضية العضوية في الحالة المثالية وحاجتها الى وقت القل للتحلل مقارنة مع الحالة الاعتيادية.

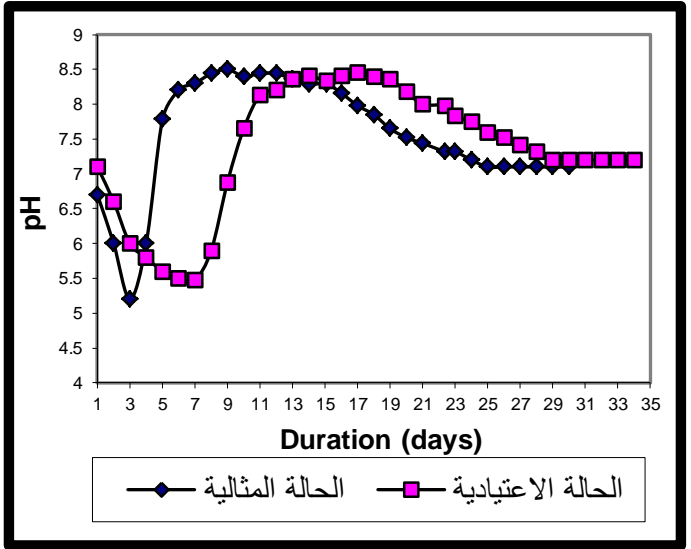

الثكل(8) تفاير الرقم الهيدروجيني لمزيج

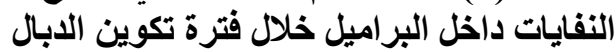
فى موسم الصيف خلال فئرة تخف

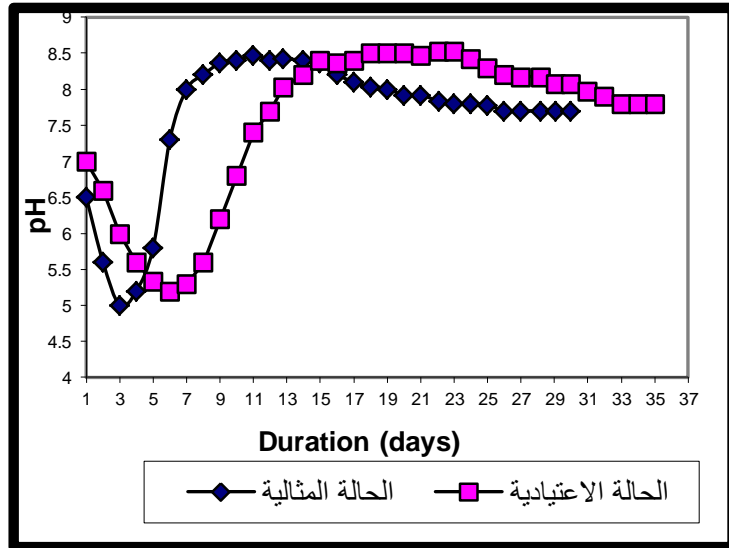

الثكل(7) تغاير الرقم الهياروجيني لمزيج

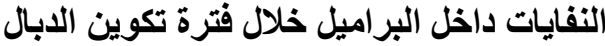

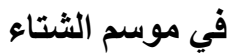
3. انخفاض حجم النفايات خلال فترة تكوين الدبال .

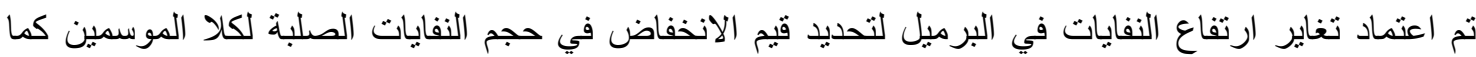

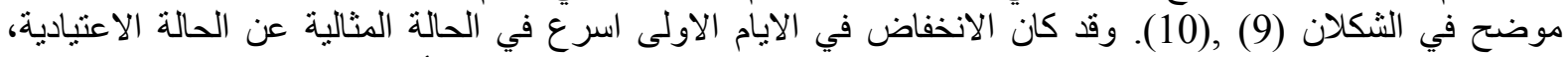
ويعزى ذللك الى سرعة تكوين الاحياء المجهرية بسبب وفرة النيتروجين حيث تقوم هذه الأحياء بتحليل المو الد العضية العضوية

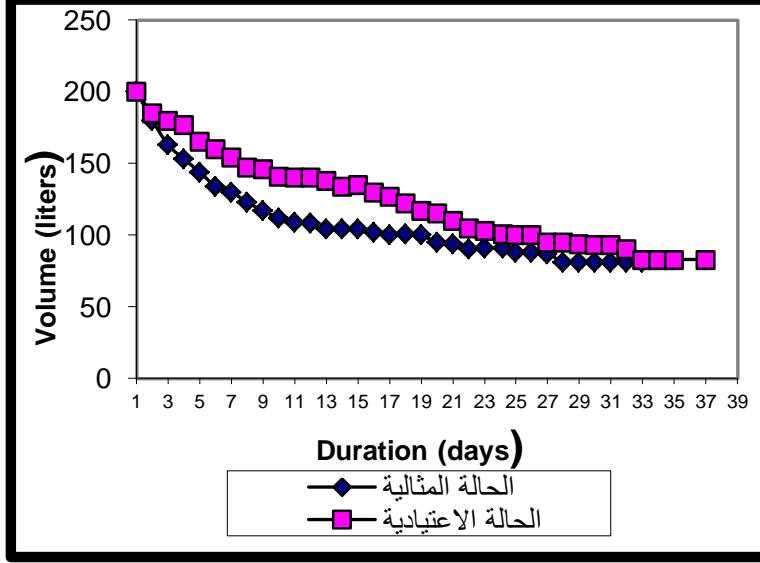

الثكل(10) تغاير حجم مزيج النفايات اثناء عملية الهضم صيفا

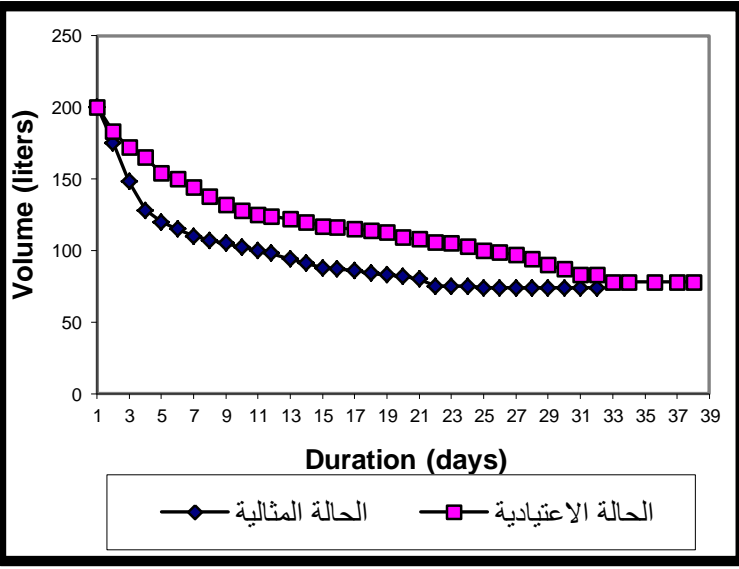

الثكل(9) تغاير حجم مزيج النفايات اثناء عملية الهضم شتاعا 


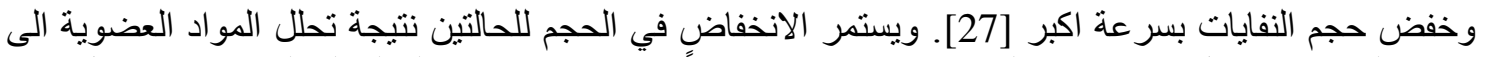

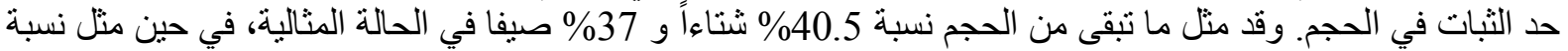
41.5\% شتاءاو 39\% صيفا في الحالة الاعتيادية، و يعزى الاختلاف البسيط للحالثين في الصيف عما هو عليه في الثتاء

الى تاثير عملية التبخير الني تزداد صيفاً.

4. تغاير محتوى الرطوبة خلال فترة تكوين الدبال

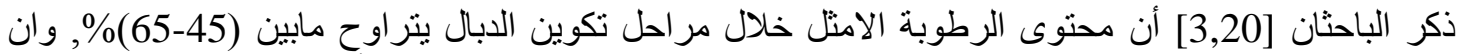

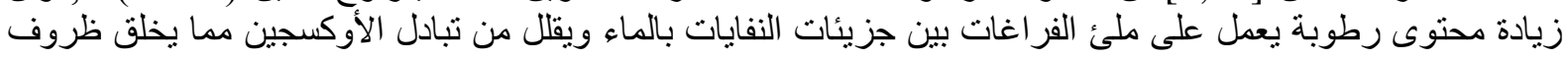

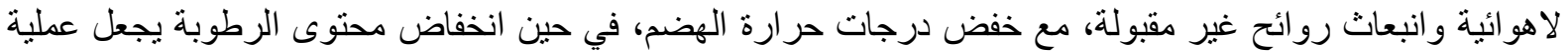

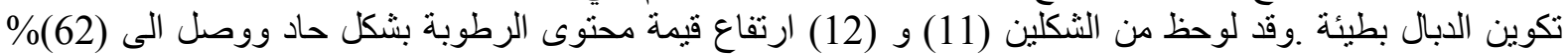

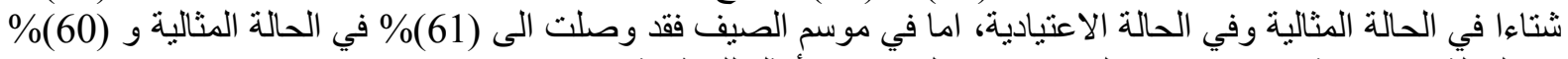

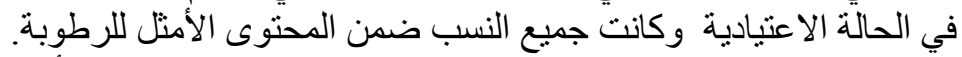

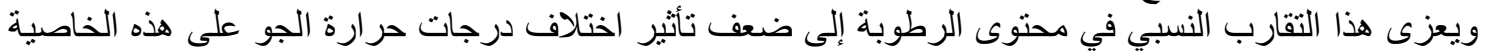

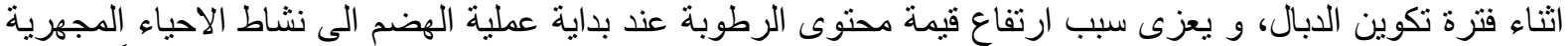
وقيامها بتحليل المو اد العضوية بسر عة و اعطاء الماء كأحد النو اتج النهائية لهذا التحلل و هذا اكده الباحث [3] ايضاً.

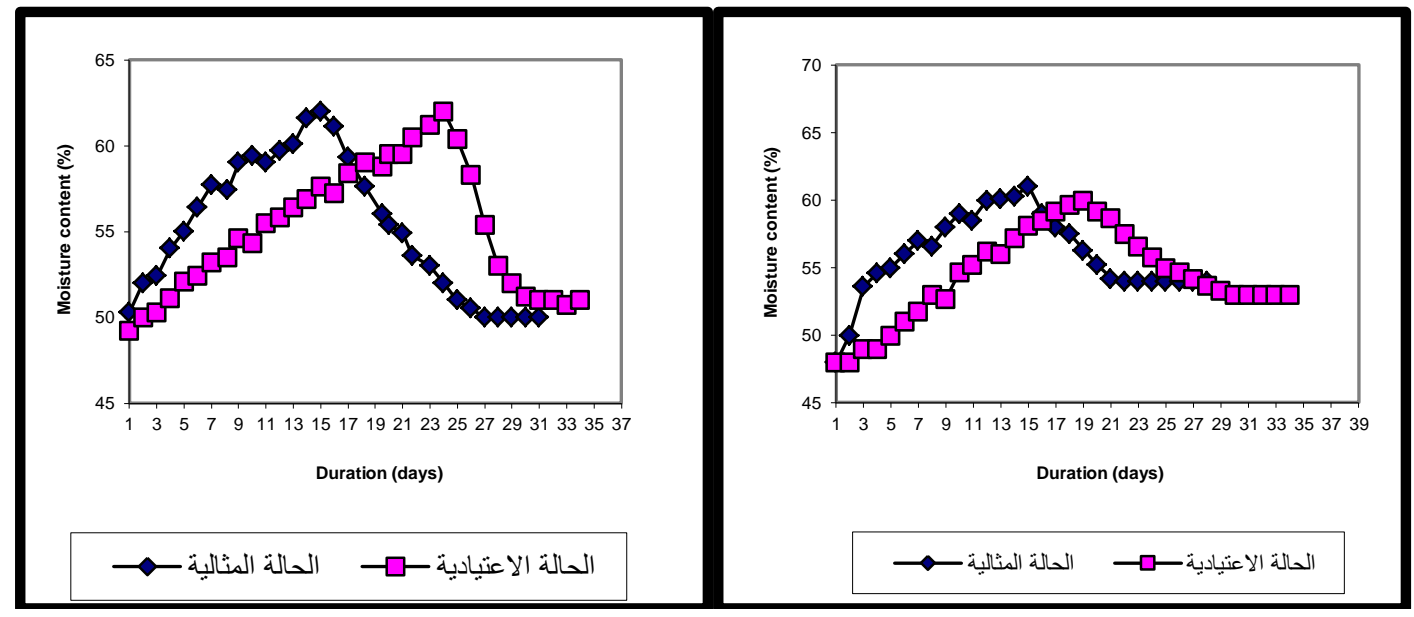

الثكل(12) تغاير محتوى الرطوبة لمزيج الثزيج

الثكل(11) تغاير محتوى الرطوبة لمزيج النفايات داخل البراميل خلايل فترة تكوين الرطوين الدبال في موسم الصيف

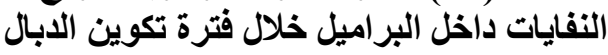

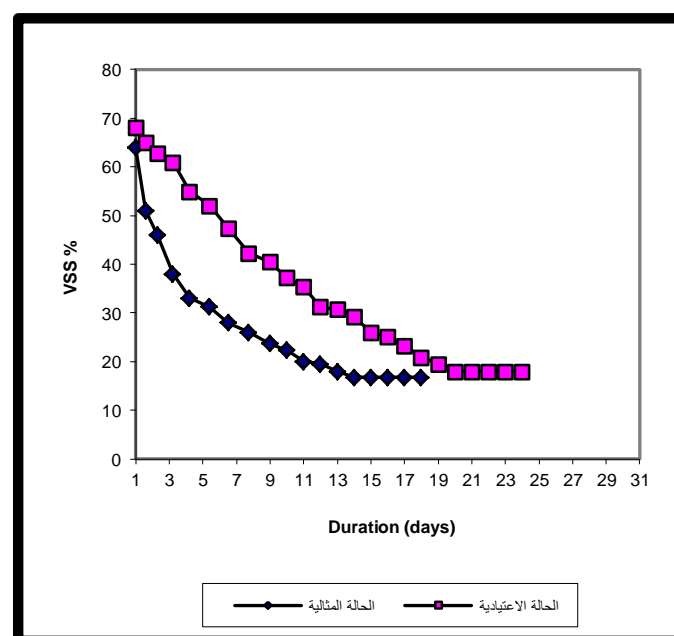

الثكل(14) تغاير VSSلمزيج النفايات داخل البراميل خلال فترة تكوين الابال في موسم الصيف لنفي

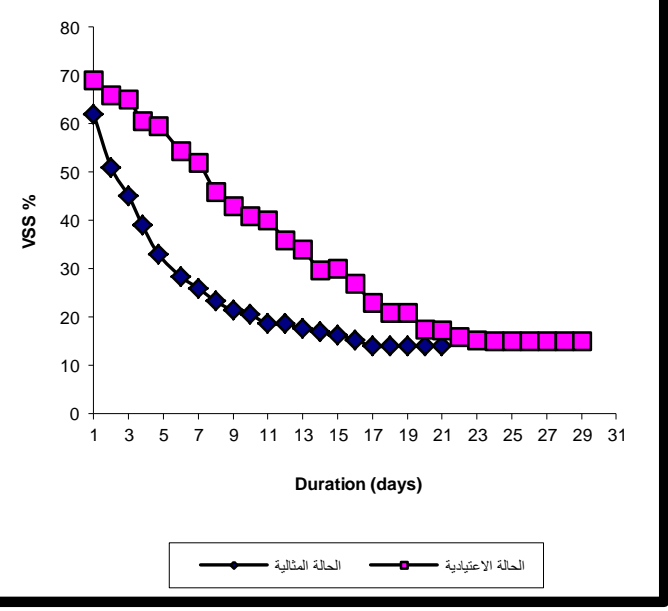

الثكل(13) تغاير VSS لمزيج النفايات داخل البراميل خلال فترة تكوين الدبال في موسم الثتاء لفئ 
5. تغاير تراكيز المواد الصلبة المتطايرة خلال فترة تكوين الابال

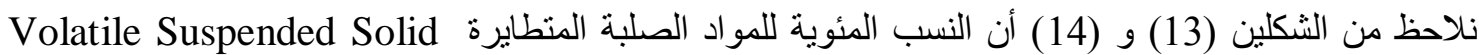

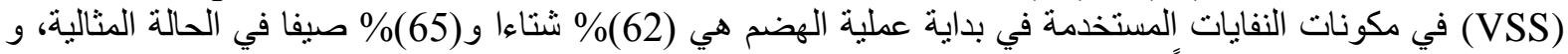

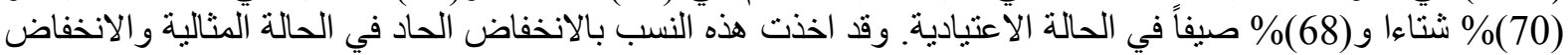

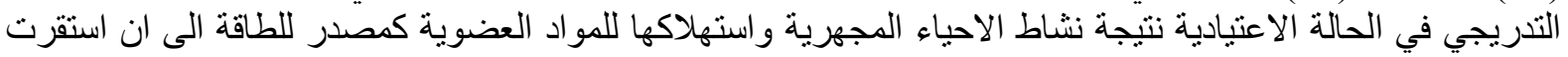

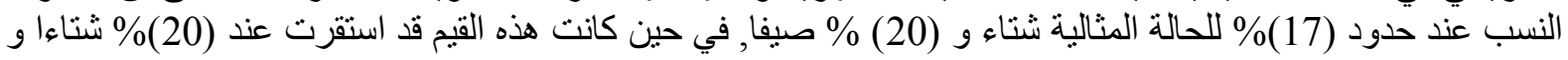

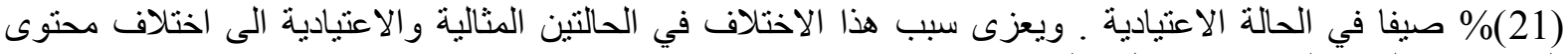

النفايات من المو اد العضوية في كل حالة . لألة

$$
\text { 6. أ. قياس نسبل الكيميائي والمكروبي للابال . }
$$

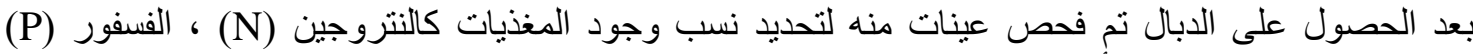

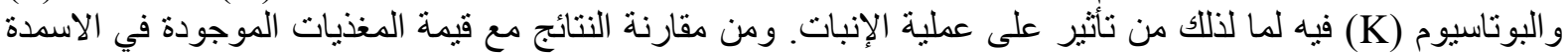

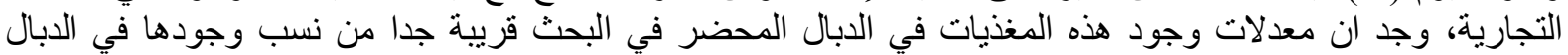

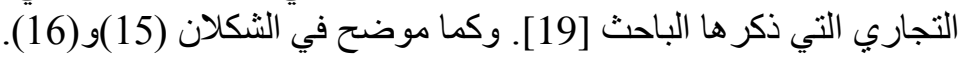
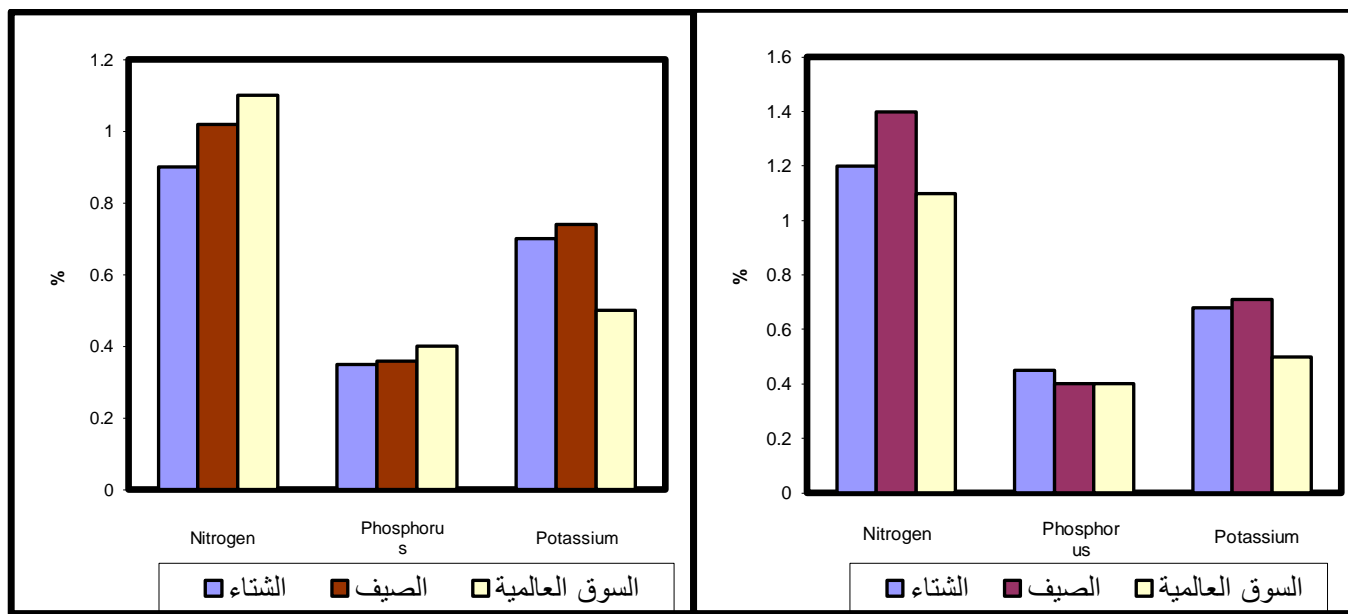

الثكل(16) معدل نسب المغذيات في الابال

الشكل(15) معدل نسب المغذيات في الابال للحالة المثالية مقارنة مع الاسمدة التجارية في المغال

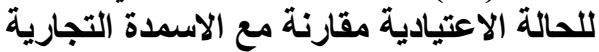

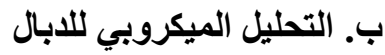

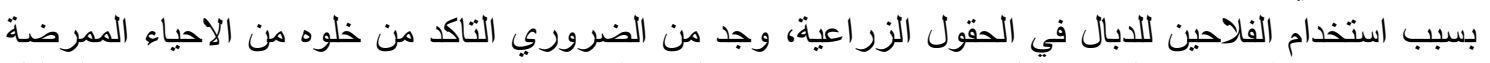

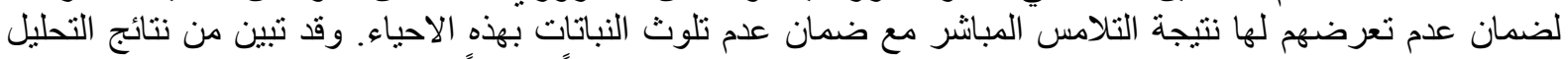

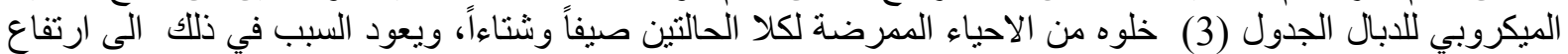

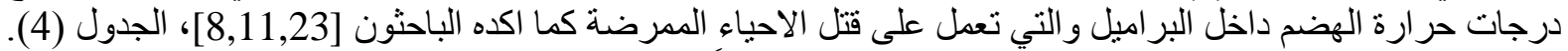

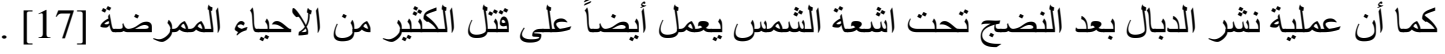

\begin{tabular}{|c|c|c|c|c|c|}
\hline \multicolumn{2}{|c|}{ عدد النموذبا / الصيفي سماد } & \multicolumn{2}{|c|}{ عدد الخلايا / غم سماد الثتوي } & \multirow{2}{*}{\multicolumn{2}{|c|}{ نوع الميكروب }} \\
\hline الحالة الاعتيادية & الحالة المثالية & الحالة الاعتيادية & الحالة المثالية & & \\
\hline $6^{*} * 10^{6}$ & $5 * 10^{6}$ & $8 * 10^{6}$ & $5.5 * 10^{6}$ & Total bacterial count & العدد الكلي للبكتريا \\
\hline Nil & Nil & $5.2 * 10^{3}$ & $4 * 10^{3}$ & Total coliform & العدد الكلي لبكتريا الكليفورم \\
\hline Nil & Nil & Nil & Nil & Fecal coliform & بكتريا القولون البرازية \\
\hline Nil & Nil & Nil & Nil & Salmonella sp. & انواع السالمونيلا \\
\hline
\end{tabular}

\section{الجدول (3) نتائج التحليل الميكروبي لنماذج الابال}


الجدول (4) يوضح قتل بعض الأحياء الممرضة الثائعة والطفيليات عند درجات حرارة معينة

\begin{tabular}{|c|c|}
\hline 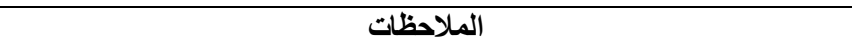 & 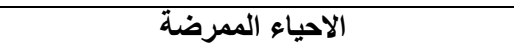 \\
\hline 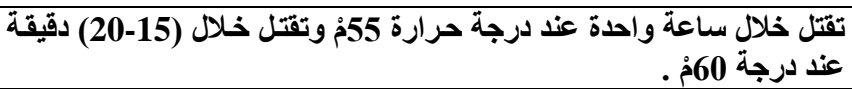 & $\begin{array}{l}\text { Fecal coliform } \\
\text { بكريا القونون البرازية }\end{array}$ \\
\hline 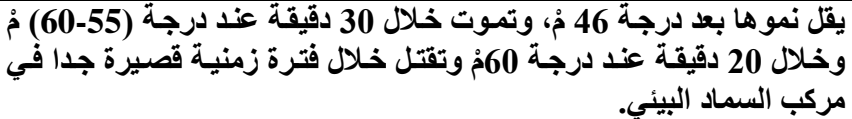 & $\begin{array}{l}\text { السالمونيلا المسبية للتيفوئيل } \\
\text { Salmonella typhosa }\end{array}$ \\
\hline 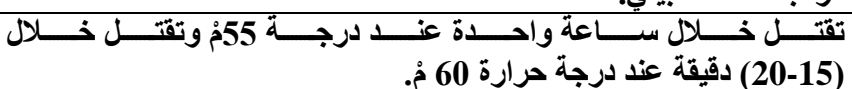 & $\begin{array}{l}\text { أنواع السالمونيلا الأخرى } \\
\text { Salmonella sp. }\end{array}$ \\
\hline تقتل خلال ساعة واحدة عثد درجة حرارة 55م & $\begin{array}{c}\text { انواع عصيات الزحار } \\
\text { Shigella sp. }\end{array}$ \\
\hline درجة خرارة تضعح دقائق عند درجة حرارة 45 مُ وتقتل خلال بضع ثواني عند & $\begin{array}{r}\text { Entamoeba أكياس الاميييا الحالة للنسيج } \\
\text { histolytica cysts }\end{array}$ \\
\hline تقتل خلال 50 دقيقةة عثد درجة حرارة 45 مُ & $\begin{array}{r}\text { الدودة الثصيةّة } \\
\text { Necator americanus }\end{array}$ \\
\hline تقتل خلال 10 دقائق عند درجة حرارة 45 م . & $\begin{array}{r}\text { عصيات التقيح } \\
\text { Streptococcus pyogenes }\end{array}$ \\
\hline تقتل خلال ساعةٌ واحدة عند درجة حرارة 50مْ & بيوض الاسكارس \\
\hline
\end{tabular}

ج. قياس تراكيز المعادن الثقيلة في نماذج الدبال

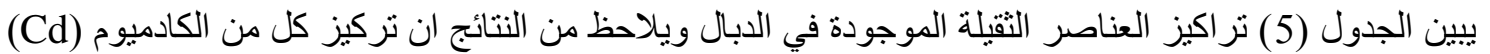
و الرصاص (Pb) و النحاس (Cu) و الخارصين (Zn) تقع ضمن محددات الدبال الصالح للاستخدام كمادة محسنة للتربة و والمشار إليها في نفس الجدول .

الجدول (5) معدل تر اكيز المعادن الثقيلة في الابال

\begin{tabular}{|c|c|c|c|c|c|}
\hline \multirow[t]{2}{*}{ المحددات [22] } & \multicolumn{2}{|c|}{ الحالة الاعتيادية } & \multicolumn{2}{|c|}{ الحالة المثالية } & \multirow{2}{*}{ العناصر الثقيلة } \\
\hline & صيف & 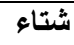 & صيف & شتاء | ش & \\
\hline $10>$ & 0.8 & 0.9 & 0.6 & 0.7 & الكادميوم Cd \\
\hline $250>$ & 71.2 & 70.8 & 62.2 & 60.3 & الرصاص Pb \\
\hline $1000>$ & 22.6 & 21.1 & 16.8 & 17.7 & النحاس Cu \\
\hline $2500>$ & 92.3 & 90.1 & 88.2 & 85.9 & الخارصين Zn \\
\hline
\end{tabular}

7. قياس وزن الدبال الجاف الناتج عن عملية الهضم .

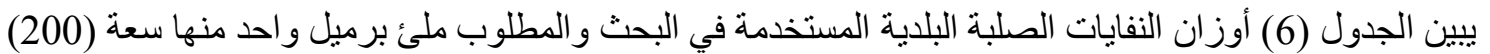
لتزر لكل حالة من حالات البحث و اوزان النائ الدبال الناتج عن كل حالة .

الجدول (6) أوزان النفايات الصلبة والدبال الناتج عنها

\begin{tabular}{|c|c|c|c|c|}
\hline \multicolumn{2}{|c|}{ الحالة الاعتيادية } & \multicolumn{2}{|c|}{ الحالة المثالية } & \multirow{2}{*}{$\begin{array}{l}\text { (كف) } \\
\text { (كف) }\end{array}$} \\
\hline صيف & شتاء & صيف & شتاء & \\
\hline 46 & 48 & 43 & 45 & كزن النفايات الصلبة لملئ برميل واحـ \\
\hline 13 & 13.5 & 14 & 14.5 & وزن الدبال الناتج من قبل كل برميل \\
\hline
\end{tabular}

8. الجدوى الاقتصادية للبحث.

أكدت الباحثة [1] أن كلفة جمع ونقل الطن الوالفاديه من النفايات الصلبة البلدية في مدينة الموصل بلغت

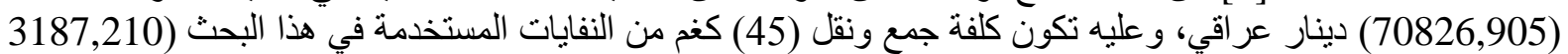

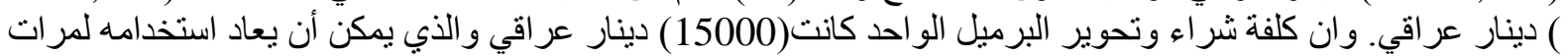




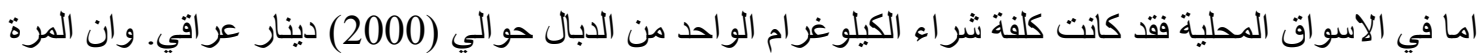
الو احدة من عملية الهضم أعطت دبال جاف وزنه (13-14.5) كغ وبهذا يمكن ان تقدر عملية تحضير الدبال بهذه الطريقة

1. عملية هضم النفايات الصلبة بهذه الطريقة أدت إلى التقليل من حجم ووزن النفايات الصلبة البرات البلدية.

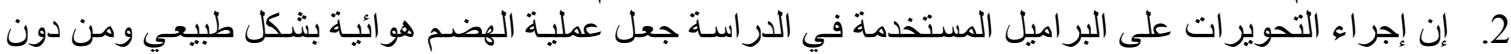

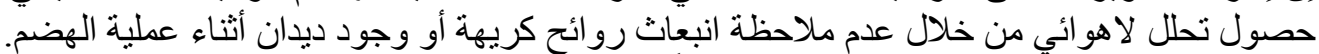

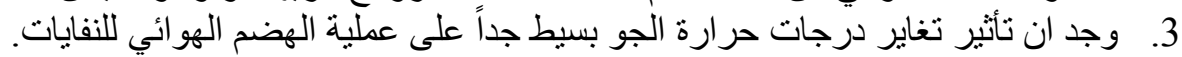

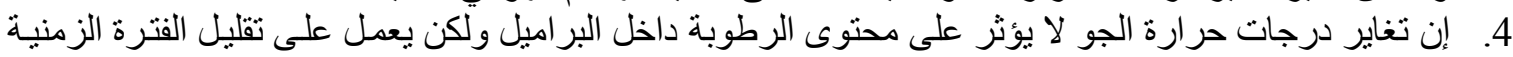

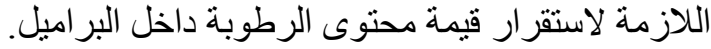
5. فترة تكوين الدبال في الحالة المثالية اقصر من الحالة الاعتبادية دادية وكانت خلال موسم الصيف اقصر ممـا عليه في

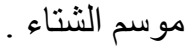

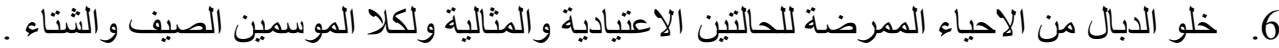
7.

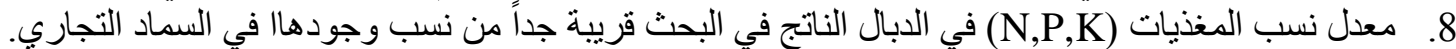

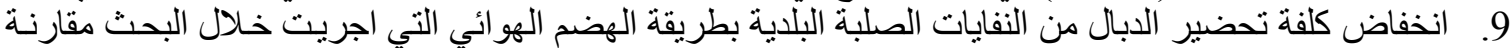

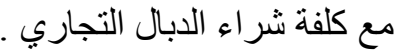

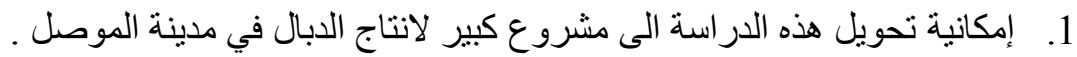

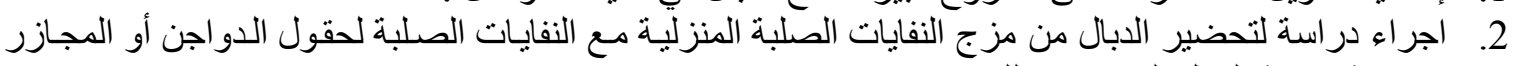

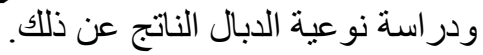

3. نوصي بعدم رص النفايات الصلبة داخل البرميل اثناء عملية الهضم و عدم تقطيع كافة النفايات باحجام صغيرة لجعل فر اغات بينها لغرض النهويات.

1- سليمان، فادية عبد القادر 2008 " ادارة النفايات الصلبة البلدية في مدينـة الموصل "، رسالة ماجستير - جامعـة

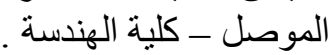

2- عباوي، سعاد عبد وحسن، محمد سليمان 1990 " الهندسة العملية للبيئة / فحوصات الماء"، دار الحكمة للطباعـة

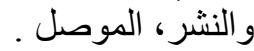

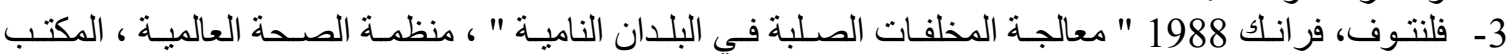

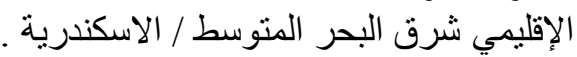

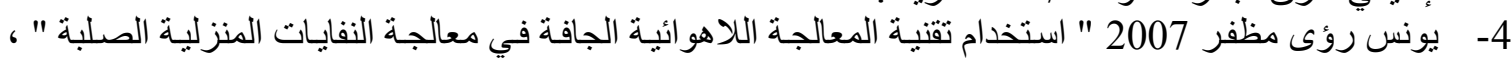
رسالة ماجستير ، جامعة الموصل ، كلية الهندسة .

5- Adewumi, I.K.; Ogedengbe, M.O.; Adepetue, J.A. and Aina, P.O. (2005) "Aerobic Composting of Municipal Solid Wastes and Poultry Manure", Journal of Applied Sciences Research, Vol.1, No.3, PP.292-297.

6- APHA; AWA; WPCF (1998) "Standard Methods for the Examination of Water and WasteWater", $20^{\text {th }}$ ed., Am. Public Healthy Assoc. Washington, D.C., USA.

7- BARC (1997)."Fertilizer recommendation Guide-1997". Bangladesh Agricultural Research Council, Soil Publication No.41.

8- Bhide, A.D. and Sundaresan, B.B., (1983) "Solid waste Management in Developing Countries" Indian National, Scientific Documentation Center, New Delhi.

9- Cooper, H.T. (2009) "Organic matter, Peat lands and Soil erosion", University of Minnesota, Unit 10, Chapter-1-.

10-Fang, M., and Wong, J.W.C. (1999) "Effect of lime amendment on availability of heavy metals and maturation in sewage sludge composting, Journal of Environmental Pollution, Vol.106, No.1, PP.83-89.

11- Golueke, C.G., (1972) "Composting", Rodale Press, Inc., Emmaus, Pa, USA. 
12- Handerson, J.O. (2001) "Anaerobic Digestion in Rular China", Canada's Office of Urban Agriculture, Vol.45, No. 4, PP.34-45.

13- Inckel, M.; Smet, P.D.; Tersmette, T. and Veldkamp, T. (2005) "The Preparation and Use of Compost", $7^{\text {th }}$. Edition, Digigrafi, Wageningen, The Netherlands.

14- Lissens, G.; Vandevivere, P.; Baere, L.D.; Biey, E.M. and Verstraete, C. (2001) "Solid Waste Digesters, Process Performance and Practice for Organic Solid Waste Digestion", Water Science and Technology, Vol.44, No.8, PP. 91-102.

15- Metcalf and Eddy, (2003) "WasteWater Engineering Treatment, disposal / reuse", $4^{\text {th }}$ Edition, McGraw-Hill, Inc., New York.

16- Minnich, J.; Hunt, M. and The Eds. Of Organic Gordening, (1979) "The Rodale Guide to Composting", Rodale Press, Emmaus, PA.

17- Moqsud, M.A. and Rahman, M.H. (2004) "Biochemical Quality of Compost from Kitchen Garbage in Bangladesh" Environmental Informatics Archives, Vol. 2, PP. 635-640. EIA04-063. International Society for Environmental Information Sciences (ISEIS-2004).

18-Moqusd, M.A.; Hayashi, S. and Rahman, M.H. (2005) "An Assessment of the Modified Composting Barrel for Sustainable Organic Waste Management in Tropical Regions", Environmental Informatics Archives, Vol. 3, PP. 130-136, EIAO5-017, International Society for Environmental Information Sciences (ISEIS-2005).

19- Muyeed, A.A. (2006) "Barrrel Composting of Domestic Solid Waste in Bangladesh : A case study", Asian Journal of Water, Environments and Pollution, Vol. 4, No. 1, PP. 133-138.

20- Rahman, M.H. (1993). "Recycling of Solid Waste in Bangladesh" The International Journal of Environmental Education \& Information. UK., Vol. 12, No. 4.

21-Raninger, B.; Rundong, Li. and lei, Feng (2006) "Activities to Apply the Europen Experience on Anaerobic Digestion of Bioorganic municipal Waste from Source Separation in China", Institute of Clean Energy and Environmental Engineering (ICEEE), HongKong University, 110034 Shenyang, China.

22-USEPA (1995) "Decision Maker's Guide to solid Waste Management, V. 2, (EPA 530-R-95-023)" Standard for Compost Produced by Aerobic Process.

23- Vesilind, P.A. and Rimer, A.E. (1981) "Unit Operations in Resource Recovery Engineering", Prentice-Hall, Inc., New Jersey.

24- Wheeler, P.A. and Rome, L.De (2002) "Waste Pre-Treatment : A Review", R \& D Technical Report No. PI-344/TR, Published by : AEA Technology Environmental, Environment Agency.

25-Wilkie, A.C. (2005) "Anaerobic Digestion : Biology and Benefites", Natural Resource, Agriculture and Engineering Service (NRAES), Vol.76, No.3, PP. 63-72.

26- Xi, B.; Li, Y.; Wei, Z.; Zhao, Y. and Liu, H. (2005) "A Study of Composting System of Municipal Solid Waste With Bio-surfactant", Journal of American Sciences, Vol.2, No.1, PP. 66-70.

27-Zheng, G.D. and Chen, T.B. (2004) "Dynamic of Lead Specialization in Sewage Sluge Composting", Journal of Water Science and Technology, Vol.50, No.9, PP. 7582.

$$
\text { تم اجراء البحث في كلية ألهندة = جامعة ألموصل }
$$

